\title{
MAP2 is differentially phosphorylated in schizophrenia, altering its function
}

\author{
M. J. Grubisha ${ }^{1} \cdot$ X. Sun ${ }^{1,2} \cdot$ M. L. MacDonald ${ }^{1} \cdot$ M. Garver ${ }^{1} \cdot$ Z. Sun ${ }^{3} \cdot$ K. A. Paris ${ }^{4}$ D. S. Patel ${ }^{4} \cdot$ R. A. DeGiosio $\mathbb{D}^{1}$. \\ D. A. Lewis $\mathbb{D}^{1} \cdot$ N. A. Yates ${ }^{5,6} \cdot$ C. Camacho ${ }^{4}$ - G. E. Homanics $\mathbb{D}^{7,8,9} \cdot$ Y. Ding $\mathbb{D}^{3} \cdot$ R. A. Sweet $\mathbb{D}^{1,10}$
}

Received: 16 April 2020 / Revised: 4 January 2021 / Accepted: 15 January 2021 / Published online: 1 February 2021

(c) The Author(s), under exclusive licence to Springer Nature Limited 2021. This article is published with open access

\begin{abstract}
Schizophrenia (Sz) is a highly polygenic disorder, with common, rare, and structural variants each contributing only a small fraction of overall disease risk. Thus, there is a need to identify downstream points of convergence that can be targeted with therapeutics. Reduction of microtubule-associated protein 2 (MAP2) immunoreactivity (MAP2-IR) is present in individuals with Sz, despite no change in MAP2 protein levels. MAP2 is phosphorylated downstream of multiple receptors and kinases identified as Sz risk genes, altering its immunoreactivity and function. Using an unbiased phosphoproteomics approach, we quantified 18 MAP2 phosphopeptides, 9 of which were significantly altered in Sz subjects. Network analysis grouped MAP2 phosphopeptides into three modules, each with a distinct relationship to dendritic spine loss, synaptic protein levels, and clinical function in Sz subjects. We then investigated the most hyperphosphorylated site in Sz, phosphoserine1782 (pS1782). Computational modeling predicted phosphorylation of S1782 reduces binding of MAP2 to microtubules, which was confirmed experimentally. We generated a transgenic mouse containing a phosphomimetic mutation at S1782 (S1782E) and found reductions in basilar dendritic length and complexity along with reduced spine density. Because only a limited number of MAP2 interacting proteins have been previously identified, we combined co-immunoprecipitation with mass spectrometry to characterize the MAP2 interactome in mouse brain. The MAP2 interactome was enriched for proteins involved in protein translation. These associations were shown to be functional as overexpression of wild type and phosphomimetic MAP2 reduced protein synthesis in vitro. Finally, we found that Sz subjects with low MAP2-IR had reductions in the levels of synaptic proteins relative to nonpsychiatric control (NPC) subjects and to Sz subjects with normal and MAP2-IR, and this same pattern was recapitulated in S1782E mice. These findings suggest a new conceptual framework for Sz-that a large proportion of individuals have a "MAP2opathy"-in which MAP function is altered by phosphorylation, leading to impairments of neuronal structure, synaptic protein synthesis, and function.
\end{abstract}

Supplementary information The online version contains supplementary material available at https://doi.org/10.1038/s41380021-01034-z.

$\triangle$ R. A. Sweet

sweetra@upmc.edu

1 Department of Psychiatry, Translational Neuroscience Program, School of Medicine, University of Pittsburgh, Pittsburgh, PA, USA

2 Tsinghua MD Program, School of Medicine, Tsinghua University, Beijing, China

3 Department of Biostatistics, University of Pittsburgh, Pittsburgh, PA, USA

4 Department of Computational and Systems Biology, University of Pittsburgh, Pittsburgh, PA, USA

5 Department of Cell Biology, University of Pittsburgh, Pittsburgh, PA, USA
6 Biomedical Mass Spectrometry Center, University of Pittsburgh, Pittsburgh, PA, USA

7 Department of Anesthesiology and Perioperative Medicine, School of Medicine, University of Pittsburgh, Pittsburgh, PA, USA

8 Department of Pharmacology \& Chemical Biology, School of Medicine, University of Pittsburgh, Pittsburgh, PA, USA

9 Department of Neurobiology, School of Medicine, University of Pittsburgh, Pittsburgh, PA, USA

10 Department of Neurology, School of Medicine, University of Pittsburgh, Pittsburgh, PA, USA 


\section{Introduction}

Schizophrenia (Sz) is highly polygenic, with common, rare, and structural variants each contributing only a small fraction of overall disease risk [1]. Thus, there is a need to identify points of convergence, i.e., pathologies shared by large proportions of individuals with $\mathrm{Sz}$, that can be therapeutically targeted to halt or reverse the synaptic [2] and functional deterioration $[3,4]$ that occurs in affected individuals. Reduced microtubule (MT)-associated protein 2 (MAP2) immunoreactivity (IR) has been reported in multiple cortical regions in Sz [5-10], leading one recent author to characterize it as a hallmark pathology in $\mathrm{Sz}$ [11]. Reduced MAP2-IR was not a consequence of common technical and clinical confounds of postmortem studies, suggesting it reflects an underlying pathogenic process $[10,12]$.

In $\sim 60 \%$ of individuals with $\mathrm{Sz}$, the reduction in MAP2IR is profound [5, 10, 12]. Even in these cases in which MAP2-IR is markedly reduced, it is not due to loss of MAP2 protein itself [10], and thus must reflect reduced detectability of MAP2 by antibody. Phosphorylation of MAP2 is known to alter its structure, function, and IR [13], and to be regulated downstream of multiple genes now established by unbiased methods as Sz risk genes [14-22]. As the predominant regulator of the dendritic MT cytoskeleton, as well as a noted coordinator between MT and actin dynamics [23], alterations to MAP2 function could explain a variety of abnormalities in dendritic structure which have been observed in Sz. Many groups have reported reduced dendritic arborization [24-28], dendritic spine density (DSD) [10, 26, 27, 29-31], and dendritic spine number [10] to be present in multiple cortical regions in Sz. These include our studies of primary auditory cortex $[10,31,32]$.

Thus, we hypothesized that MAP2 phosphorylation would be altered in Sz and alter MAP2 functions, providing a potential hub for pathogenesis. To evaluate this, we undertook a phosphoproteomic analysis of MAP2 in primary auditory cortex of $\mathrm{Sz}$ and nonpsychiatric control (NPC) subjects. We identified 18 unique phosphopeptides. Levels of nine of these were significantly altered in Sz. The 18 phosphopeptides grouped into three modules using network analysis, each with a distinct relationship to clinicopathologic correlates of disease. We designed a series of experiments to further investigate the most altered phosphorylation site, serine 1782 (pS1782), finding that phosphomimetic mutation at this site reduces microtubule binding. In a phosphomimetic knock-in mouse model of pS1782 (S1782E), we found reduced dendritic length, complexity, and spine density. Using MAP2 co-immunoprecipitation (co-IP) coupled with mass spectrometry, we found that the MAP2 interactome was enriched for proteins regulating translation. This association was shown to be functional as overexpression of wild type (WT) and phosphomimetic MAP2 reduced protein synthesis in vitro. Finally, we found that $\mathrm{Sz}$ with profound reductions in MAP2-IR (MAP2-IR $\mathrm{LOW}_{\mathrm{L}}$ ) was characterized by reductions in the levels of synaptic proteins relative to both NPC and SZ with normal MAP2-IR (MAP2-IR $\mathrm{NL}_{\mathrm{NL}}$ ) subjects, and this same pattern was recapitulated in S1782E mice, although to a lesser degree.

\section{Results}

\section{MAP2 is differentially phosphorylated in auditory cortex in $\mathrm{Sz}$}

We conducted an unbiased proteomic survey of MAP2 phosphorylation in tissue obtained from right Heschl's gyrus (primary auditory cortex (A1)) obtained from Sz subjects with either profoundly reduced MAP2-IR in left Heschl's gyrus (MAP2-IR $\mathrm{L}_{\mathrm{LOW}}, N=11$ ) [10] or normal MAP2-IR (MAP2-IR $\left.{ }_{\mathrm{NL}}, N=5\right)$, and from NPC $(N=16)$ subjects (see Fig. 1a and Table S1 for subject characteristics). We identified 18 unique MAP2 phosphopeptides in our samples (Table S2), confirmed by manual sequencing of MS2 spectra, 8 of which were significantly altered $(q<$ $0.05)$ in MAP2-IR $\mathrm{LOw}_{\mathrm{Lz}} \mathrm{Sz}$ subjects relative to NPC subjects (Table S2). In MAP2-IR $\mathrm{NL}_{\mathrm{NL}} \mathrm{Sz}$ subjects, changes in phosphopeptide levels were mostly attenuated, although in the combined $\mathrm{Sz}$ group a total of nine phosphopeptides now reached significance (Fig. 1b upper panel, Table S2). The most altered phosphopeptide, VDHGAEIITQS $[+80]$ PGR, containing a single phosphorylation at serine 1782 (pS1782, numbering per the canonical MAP2b isoform, UniProt identifier: P11137-1), was increased up to nearly sevenfold relative to NPC subjects. Elevated levels of MAP2 phosphopeptides were largely unassociated with potential tissue and clinical confounds (Table S3 and Fig. S1) with two notable exceptions. First, levels of VDHGAEIITQS[+80] PGR were significantly lower in Sz subjects taking antipsychotics at time of death than in those subjects off antipsychotics, raising the possibility that antipsychotic treatment could act, in part, through effects on phosphorylation of S1782. However, this effect was not recapitulated by a monkey model of long-term antipsychotic exposure [33], nor did this model induce elevations in any of the phosphopeptides found to be elevated in $\mathrm{Sz}$ in our current study (Fig. 1a, lower panel). Second, phosphopeptide abundance may be affected by postmortem interval (PMI). Thus, we further evaluated this potential confound in two ways. We first tested the effect of PMI on phosphopeptide abundance in our subjects, finding no significant associations (all $q>0.1$, Table S3). Second, we surveyed 
Fig. 1 MAP2 is differentially phosphorylated in Sz. a Data for continuous variables are presented as group average \pm standard deviation for each group $(\mathrm{NPC}=$ nonpsychiatric control, SZ MAP2-IR ${ }_{\text {LOW }}$, SZ MAP2-

$\left.\mathrm{IR}_{\mathrm{NL}}\right)$. There was no significant difference amongst groups on any of the variables (all $p>0.1$ ). b Top panel shows Sz vs NPC, phosphopeptides are denoted by crosses at the position of their starting amino acid. Nine phosphopeptides had significant alterations (FDR corrected $q<0.05$, green crosses). Note significantly altered phosphopeptides were present in the Projection domain (unique to high MW MAP2A/B) and surrounding the MT-binding domain. Red arrow denotes pS1782. No phosphopeptides were detected in the MT-binding domain. Bottom panel shows antipsychotic-exposed (AP) vs sham-exposed monkey. Three peptides were nominally significant ( $p<0.05$, red crosses). Most peptides were identified in both species (indicated by alignment on $x$-axis), but peptides significantly altered in $\mathrm{Sz}$ did not correspond to those increased by antipsychotic exposure. $x$-axis shows amino acid location in $\mathrm{MAP} 2 \mathrm{C}$ and in canonical MAP2B. MAP2 functional domains are denoted. $\mathbf{c} \log 2$ area under the curve (AUC) values for significant MAP2

phosphopeptides across increasing postmortem intervals in mouse tissue demonstrates relatively linear stability that is easily accounted for in our PMI matching of subjects. The one exception to these linear trends is RLS[+80]NVSS[+80]SGS[+80] INLLESPQLATLAEDVTAALAK. Individual peptides indicating phosphorylated residue (s) are listed in the legend below the graph. Data shown are \pm SEM from $N=4$ samples per timepoint. a.

\begin{tabular}{|c|c|c|c|}
\hline Diagnostic Group & NPC & $\begin{array}{c}\text { SZ MAP2- } \\
\mathbf{I R}_{\text {Low }}\end{array}$ & $\begin{array}{c}\text { SZ MAP2- } \\
\mathbf{I R}_{\mathbf{N L}}\end{array}$ \\
\hline Number & 16 & 11 & 5 \\
\hline Sex & $12 \mathrm{M}, 4 \mathrm{~F}$ & $8 \mathrm{M}, 3 \mathrm{~F}$ & $4 \mathrm{M}, 1 \mathrm{~F}$ \\
\hline Race & $10 \mathrm{~W}, 5 \mathrm{~B}, 10$ & $8 \mathrm{~W}, 3 \mathrm{~B}$ & $3 \mathrm{~W}, 2 \mathrm{~B}$ \\
\hline Age (years) & $44.2 \pm 11.6$ & $50.1 \pm 11.9$ & $47.4 \pm 15.7$ \\
\hline PMl (hours) & $16.0 \pm 6.9$ & $16.1 \pm 7.6$ & $14.6 \pm 9.5$ \\
\hline pH & $6.8 \pm 0.2$ & $6.5 \pm 0.4$ & $6.4 \pm 0.2$ \\
\hline Storage time (months) & $133.6 \pm 41.6$ & $130.0 \pm 28.3$ & $111.6 \pm 43.0$ \\
\hline
\end{tabular}

b.

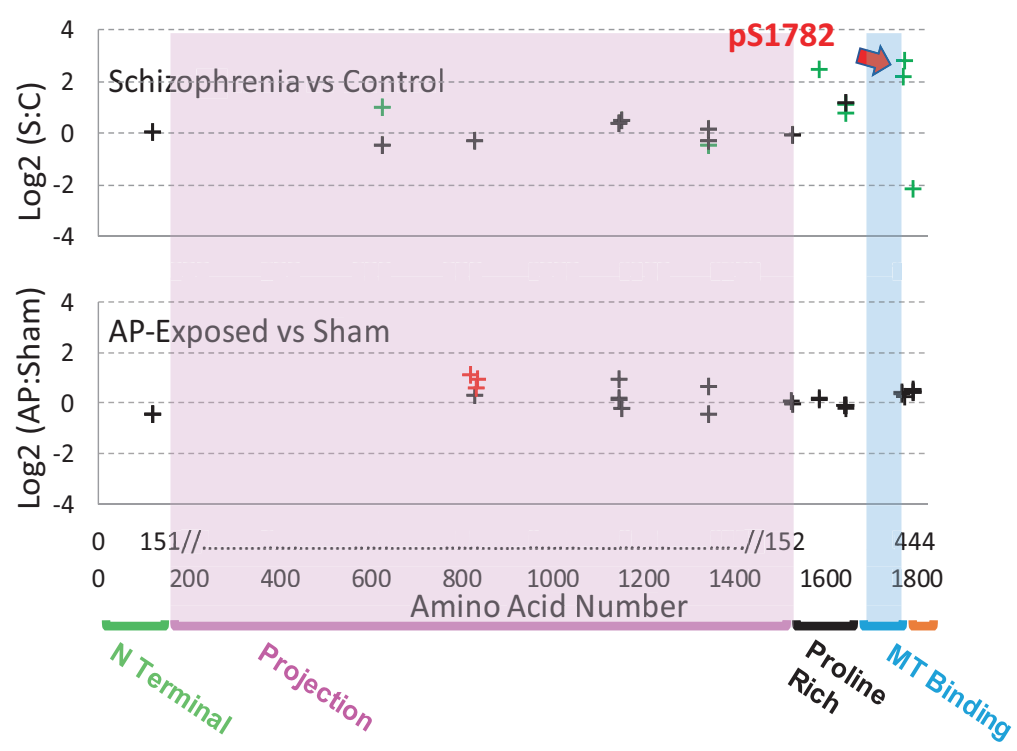

c.
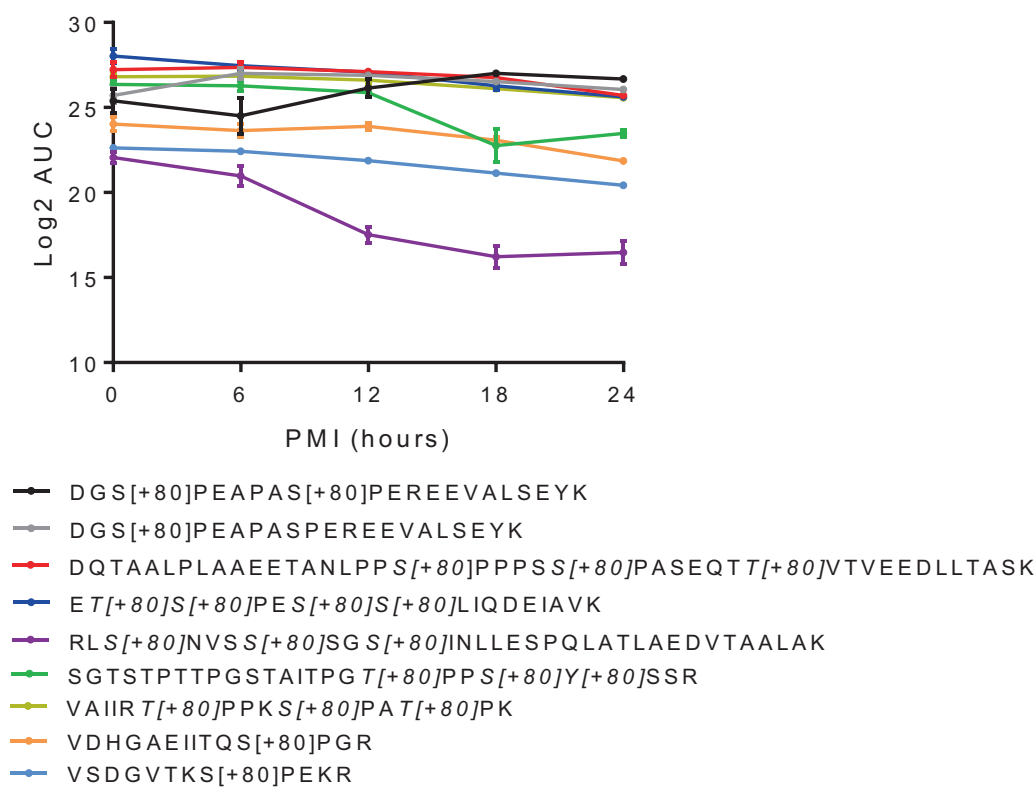

MAP2 phosphopeptide abundance in a mouse model of increasing PMI. We detected nine MAP2 phosphopeptides in this model. Figure 1c shows the detected MAP2 phosphopeptides, eight of which demonstrate stable or linear changes over time (and thus readily accounted for by PMI matching in our subjects). The exception was peptide 
(RLS[+80]NVSS[+80]SGS[+80]INLLESPQLA-

TLAEDVTAALAK) which had a nonlinear decay.

We next applied weighted gene coexpression network analysis (WGCNA) [34] to the MAP2 phosphopeptide data from the $\mathrm{Sz}$ and NPC subjects. MAP2 phosphopeptides clustered into three modules (Fig. S2). We then used these three modules to compute eigenpeptide values for all subjects and tested these values for their associations with known pathological features of disease, namely decreased DSD and decreased synaptic protein levels, both of which had been previously measured in these subjects [31, 35]. Furthermore, socioeconomic status (SES) was included as a proxy measure for functional impairment in $\mathrm{Sz}$ [36], thus we also tested the eigenpeptide values for their association with subject SES (Fig. 2a). Levels of phosphorylation of blue module sites, which include pS1782, are associated with lower spine density, reduced synaptic protein levels, and poorer outcomes (lower SES). In contrast, increasing phosphorylation of brown module sites, which are only present in the MAP2a and MAP2b isoforms, are correlated with better phenotypic outcomes. Turquoise module
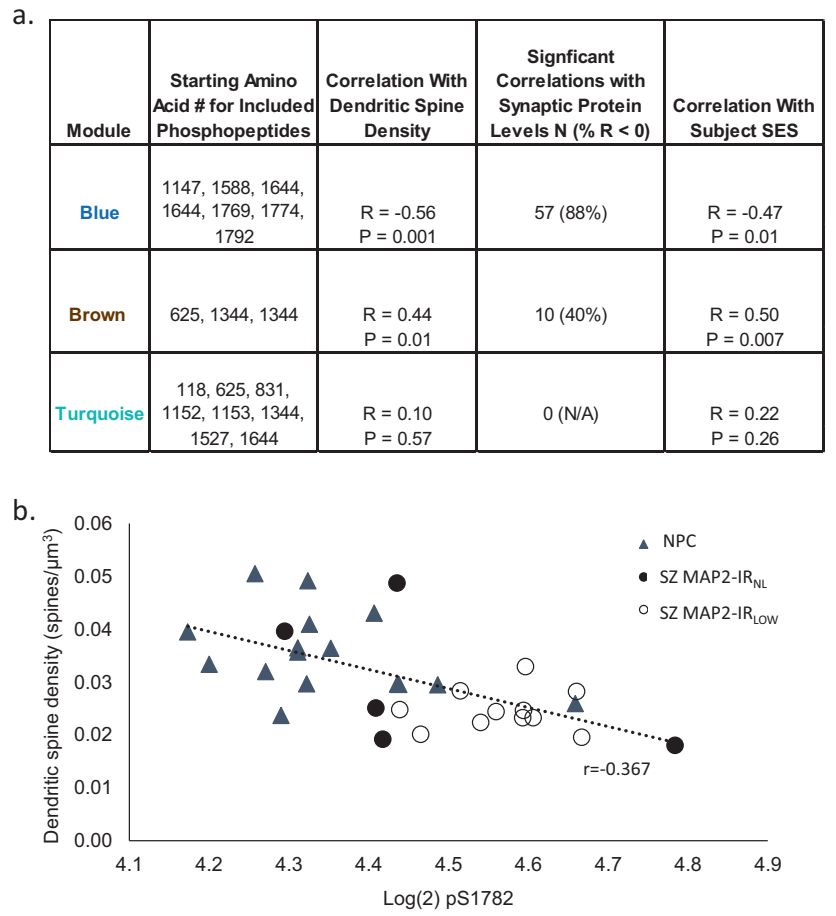

Fig. 2 Association of phosphopeptide modules with clinical and pathologic phenotypes. a For each module the association with small spine density, synaptic protein levels and SES are shown. Significant correlations with synaptic protein levels were defined as $q<0.05$, and the percent of those significantly correlated synaptic proteins that were negatively correlated with each module is shown (\% with $r<0$ ). b pS1782 negatively correlates $(r=-0.61, p=0.0002)$ with dendritic spine density. NPC nonpsychiatric control, Sz subjects grouped by MAP2 immunoreactivity as either normal (MAP2- $\mathrm{IR}_{\mathrm{NL}}$ ) or low (MAP2-IR LOW $_{\text {). }}$ phosphopeptides show little relationship to the measured phenotypes.

\section{Phosphorylation of MAP2 at S1782 alters its predicted structure and reduces MT binding}

The phosphopeptide with the most elevated levels in $\mathrm{Sz}$ was VDHGAEIITQS ${ }^{[\mathrm{P}]}$ PGR, phosphorylated at S1782. This peptide belongs to the blue module, which includes negative correlations with DSD and synaptic protein levels. Figure $2 \mathrm{~b}$ shows the negative correlation $(r=-0.61, p<$ $0.001)$ between DSD and pS1782 levels. Furthermore, S1782 is conserved in the MAP2 homolog MAP tau (MAPT), as S396 (numbering by common convention as per Isoform tau-F, UniProt identifier: P10636-8), which when phosphorylated confers synaptic pathology [37-40]. We used all atom molecular dynamics (MD) simulations to predict potential effects of pS1782 on MAP2 structure. Like its homolog tau, structure of the intrinsically disordered MAP2 is difficult to characterize. Because MAP2 and tau share high sequence homology, to validate our model we first checked for consistency with available information in both MAP2 [41, 42] and tau [43, 44]. For this validation, we relied on the known effect of phosphorylation at T231 in tau (homologous to T1649 in MAP2). For example, our model of pT1649 MAP2 revealed a salt bridge interaction between pT1649 and R1648 and helical propensity for the region ${ }^{299}$ ATPKQLRLR ${ }^{307}$, both of which predictions recapitulated prior observations for the corresponding residues in tau (data not shown) [45-48]. We then examined phosphorylation at $\mathrm{S} 1782$ by simulating a region of MAP2 containing residues 1718 to 1827 (covering the C-terminal domain). Our models indicated two structural changes upon phosphorylation of S1782: (a) an antiparallel $\beta$ hairpin structure observed in WT MAP2 opened up to create a solvent-exposed extended $\beta$ structural conformation between A1776 and S1782 in pS1782 phosphorylated MAP2, and (b) a region with helical propensity in WT MAP2 was instead found to prefer a solvent-exposed extended $\beta$ structural conformation between residues V1755 and A1770 in the pS1782 ensemble (Fig. 3). The homologous residues $\mathrm{K} 369$ to $\mathrm{A} 384$ in tau are part of the Cterminal (residues K369 to S400) that flank the MT-binding (MTB) region and have been proposed for positioning tau on the MT surface allowing MT binding [49-51]. More recently, NMR showed that pS396 tau had weaker tubulin affinity than the WT tau peptide with signal attenuation centered around residues H374, F378, H388, and Y394 [52]. Based on these data, we predicted that MAP2 pS1782 decreases MT binding.

To empirically evaluate these predictions, HEK293 cells, which lack endogenous MAP2, were transfected with plasmid containing either WT MAP2c (UniProt identifier: 

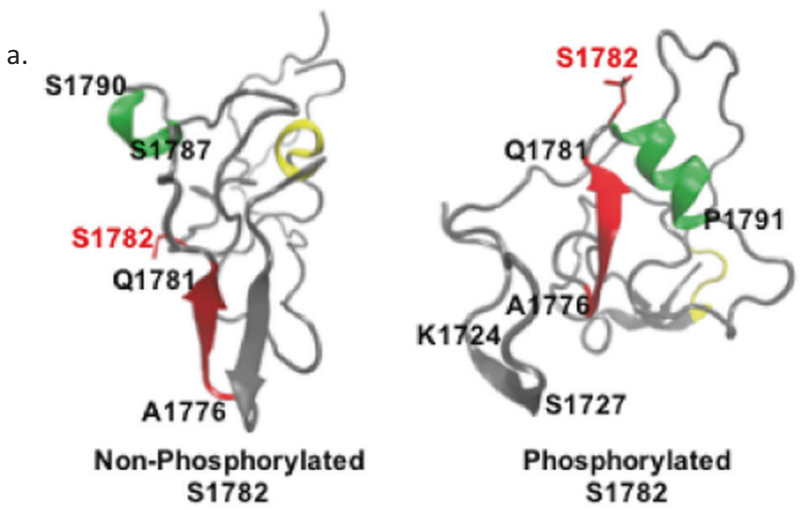

b.
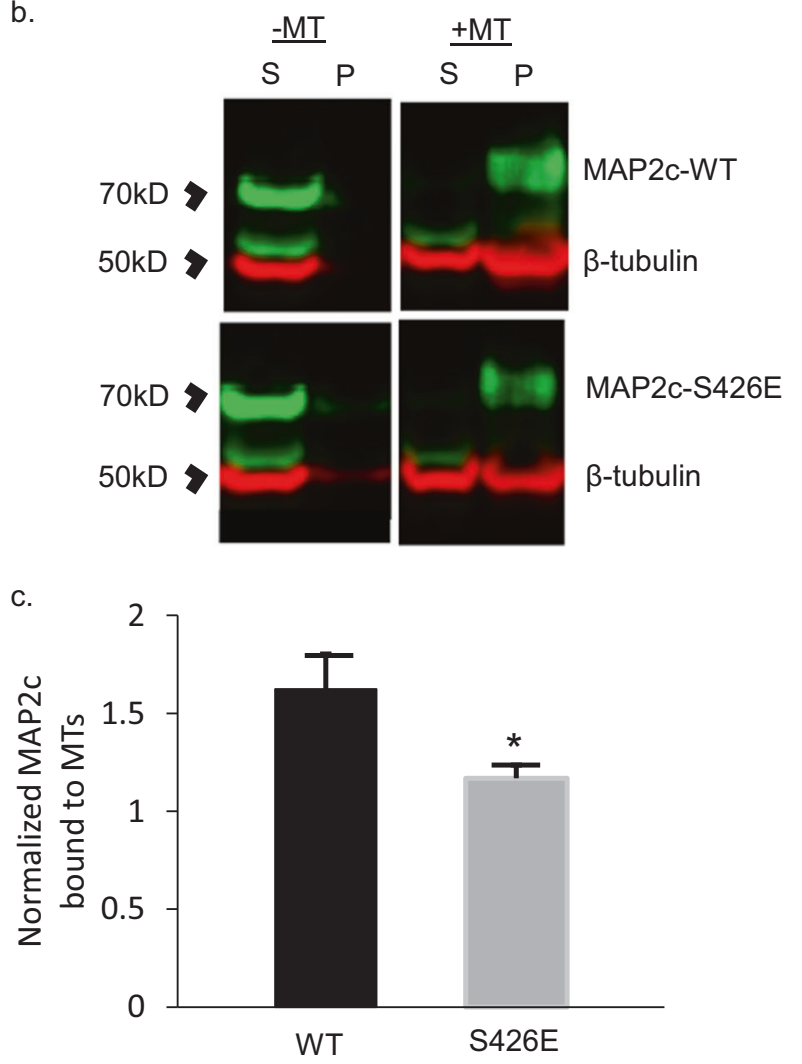

Fig. 3 Computational modeling of MAP2 pS1782 alters predicted structure and reduces microtubule binding. a Snapshot of the Cterminal domain of MAP2. Amino acids A1776 to Q1781 form an extended $\beta$ strand (red $\beta$ strand) that is occluded by an opposing $\beta$ strand. In much of the nonphosphorylated ensemble, there is found to be helical propensity in or near regions S1759 to R1765 (yellow) which is not found in the phosphorylated ensembles. In pMAP2 (pS1782), the $\beta$ strand at A1776 to Q1781 is no longer occluded by another $\beta$ strand; this is predicted to reduce microtubule binding and enhance interactions with other proteins. The effect of phosphorylation is recapitulated by phosphomimetic mutation S1782E (data not shown). b Reduced MT binding in MAP2c with the phosphomimetic mutation S426E, homologous to S1782 in full-length MAP2b relative to MAP2c-WT. $30 \mu \mathrm{L}$ of cell lysate from transiently transfected HEK293 cells was subjected to in vitro MT-binding assay and supernatant $(\mathrm{S})$ and pellet $(\mathrm{P})$ fractions were subjected to SDS-PAGE. c Densitometric analysis of gels shows decreased MT binding in the S426E mutant compared to WT. Data shown are from three independent experiments, \pm SEM. $* p<0.05$.
P11137-2) or MAP2c with the phosphomimetic mutation S426E, homologous to $\mathrm{S} 1782$ in full-length MAP2b (see "Methods" for plasmid construct information), and a MTB assay was performed. The results of the MTB assay are shown in Fig. 3b, c and confirm the computationally predicted reduction of MT binding by S426E MAP2c.

\section{S1782E reduces dendritic length, complexity, and spine density in vivo}

Our studies in the nonneuronal HEK293 cells, while able to inform on MTB properties of phosphomimetic MAP2, could not inform whether such effects would have an impact in the specific intracellular environment of neurons. Because MAP2 is a critical determinant of dendritic structure via its canonical function of regulating MT polymerization dynamics [13, 53-55], we hypothesized that the disrupted MT binding caused by pS1782 would cause reductions in dendritic architecture similar to those seen in $\mathrm{Sz}$ (reviewed in [2]). To test this, we used CRISPR/Cas9 gene editing to introduce the phosphomimetic mutation (serine to glutamate, S1782E) in a mouse model (Fig. S3) to allow for in vivo studies of dendritic structure. Reduced DSD has been consistently reported in auditory cortex in $\mathrm{Sz}$ [2], thus we initially focused on layer three PCs in auditory cortex for dendritic reconstructions. Using Golgi staining, we compared dendritic arbor size in 12-week heterozygous S1782 $\mathrm{E}^{+/-}$mice $(N=10,5$ male, 5 female) with WT littermates ( $N=10,5$ male, 5 female). A total of five neurons per animal were collected. Dendritic reconstructions were manually traced from image stacks offline using Neurolucida software (Microbrightfield, Inc) and analyzed via Sholl analysis using NeuroExplorer (Microbrightfield, Inc). There were no significant effects of sex or phase of estrus cycle, thus sexes were combined to generate $N=10$ animals/ genotype for final analyses. We found that $\mathrm{S} 1782 \mathrm{E}^{+/-}$mice had significant reductions in basal dendritic length, complexity, and spine density compared to WT (Fig. 4). Despite the effects on dendritic structure, phosphomimetic mutation at S1782 did not reduce MAP2-IR in our mouse model. We quantified MAP2-IR in a small cohort of WT and MAP2 S/ $\mathrm{E}+/+$ mice and did not find a significant difference between genotypes (mean change in MAP2 intensity $1.96 \pm 16 \%$, data not shown).

\section{MAP2 interacts with ribosomal complexes and inhibits protein synthesis}

MAP2 binding to MTs can sequester MAP2 and its binding partners [54]. Conversely, reduced MAP2 binding to MTs increases the availability of MAP2 to associate with alternate interaction partners [56], creating what in essence is a 
Fig. $4 \mathrm{S1782E}^{+/-}$mice demonstrate reduced basilar arbor branching and length. a Representative single plane Golgi images and corresponding reconstructions of L3 PCs generated from wild-type (left) and S1782E $\mathrm{E}^{+/-}$(right) mice. b $\mathrm{S} 1782 \mathrm{E}^{+/-}$mice show reduced branching and length in basilar arbors compared to wild type. c Representative single plane Golgi images of a segment of basilar dendrite from a wild-type (left) and S1782 $\mathrm{E}^{+/-}$mouse (right). Quantitatively, S1782 $2^{+/-}$ mice show a reduction in spine density along basilar branches compared to wild type. Sholl data shown are averaged across $N=$ 10 animals/genotype (animal values generated by averaging five neurons/animal) \pm SEM. Spine data shown are generated from the average value per animal across $N=10$ animals/ genotype (animal values generated from three to five neurons/animal \pm SEM. $* p<0.05$. a.

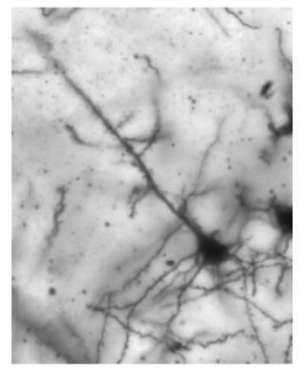

wildtype

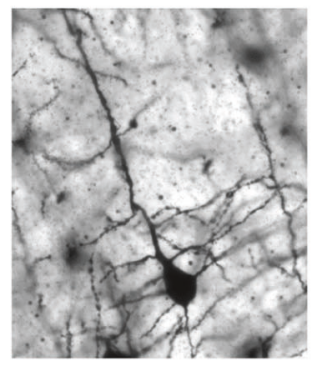

MAP2 S/E b.
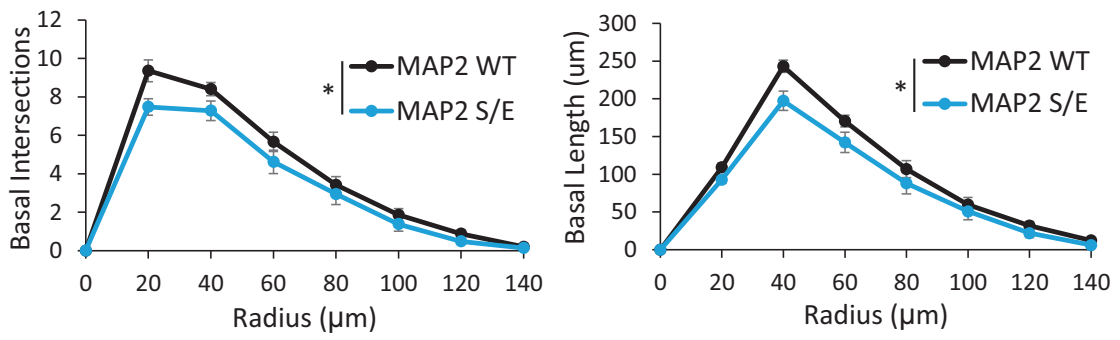

c.
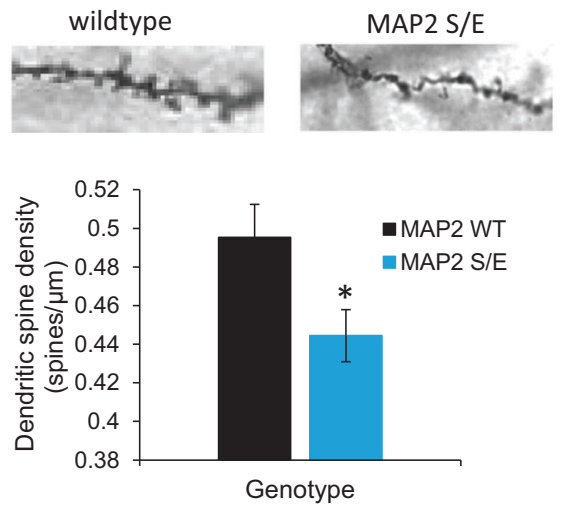

gain of function of these latter effects. We therefore sought to use an unbiased proteomic screen of the MAP2 interactome to identify additional potential interaction partners. co-IP of MAP2 from RNAse-treated whole brain homogenate from $\mathrm{C} 57 \mathrm{~B} 16 \mathrm{~J}$ mice $(N=3$ mice, six hemispheres total as biological samples) resulted in identification of 590 proteins that were potential interactors of MAP2 $(q<0.05)$ for MAP2 IP compared to no antibody control (Fig. 5, see also Fig. S4 and Table S4). Our unbiased approach highlighted an interaction previously observed in neurons, although underappreciated, between MAP2 and ribosomal complexes [57]. Functional annotation analysis [58] of these proteins revealed enrichment for terms related to translation (e.g., GO:0006412 - translation, corrected $p=$ 1.4E-30, $\quad N=71$ proteins) and ribosome (e.g., GO:0005840-ribosome, corrected $p=3.2 \mathrm{E}-27, N=46$ proteins). Table S5 shows the three highest scored GO categories within the top eight functional annotation clusters.
Based on the above association of MAP2 with ribosomal complexes, we next hypothesized that MAP2 may play a role in translational regulation. To test this, we measured incorporation of puromycin, an indicator of new protein synthesis [59]. Expression of both WT or S426E MAP2c in HEK293 cells suppressed new protein synthesis compared to expression of eGFP alone, though the magnitude of this effect was slightly greater in S426E (Fig. 5b). Because this finding was derived from study of HEK293 cells, we once again undertook to assess whether similar effects might be observed in neurons. Previous work from our lab using a targeted proteomics assay in synaptosomes prepared from A1 of Sz and NPC subjects found widespread reductions in the levels of multiple synaptic proteins [60]. We then generated synaptosome preparations from cerebral cortex of WT and S1782E $+/+$ mice and assayed protein levels with the same targeted proteomics assay. Figure $5 \mathrm{c}$ shows that mice with the phosphomimetic mutation S1782E have reduced levels of multiple synaptic proteins. We then undertook to reanalyze the data in our $\mathrm{Sz}$ 

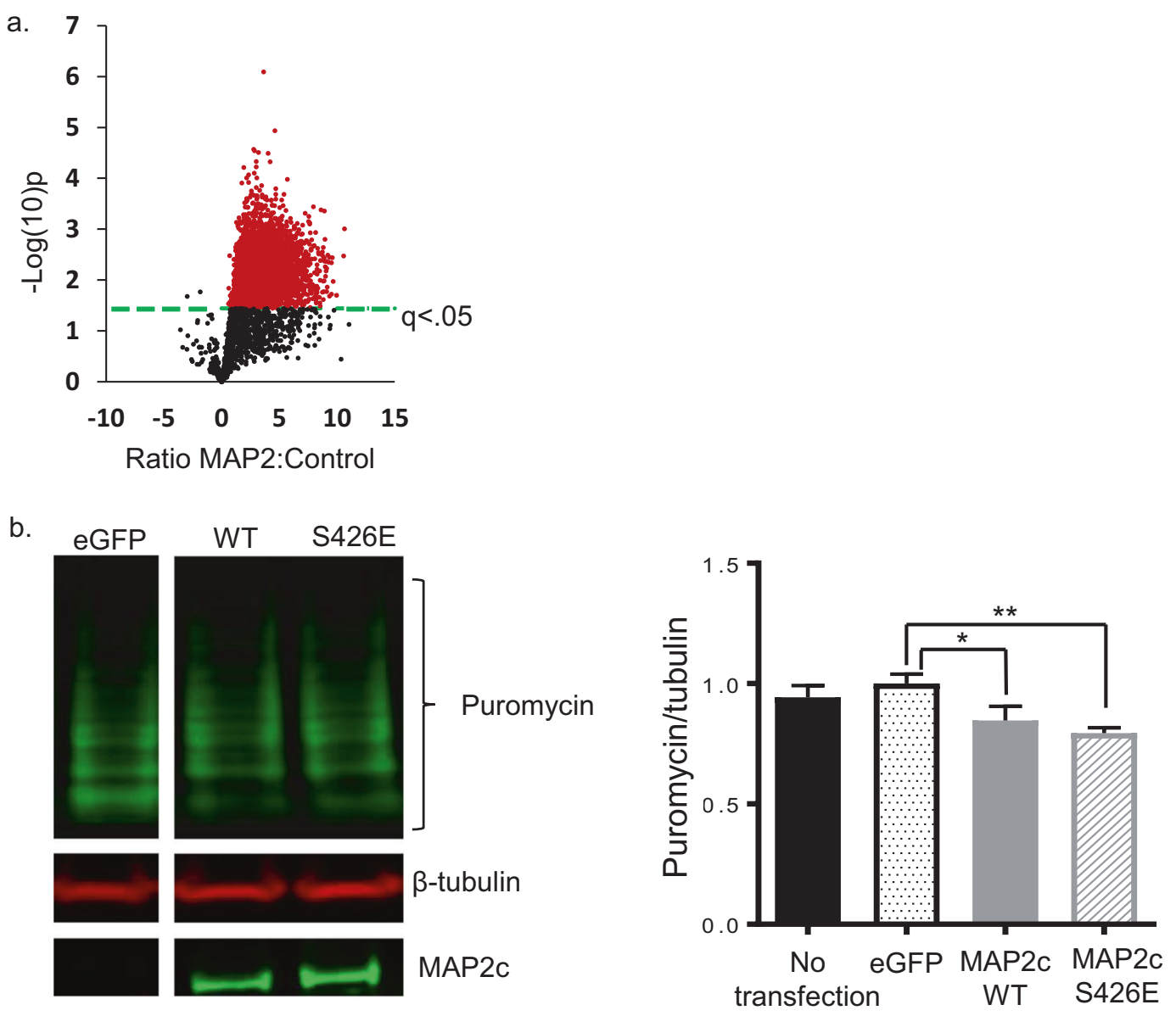

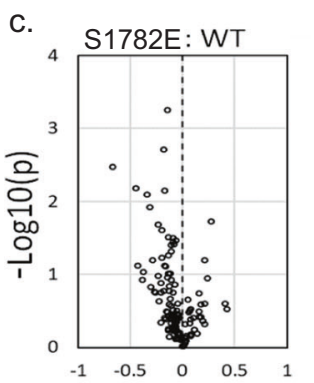

Log2 Fold Change

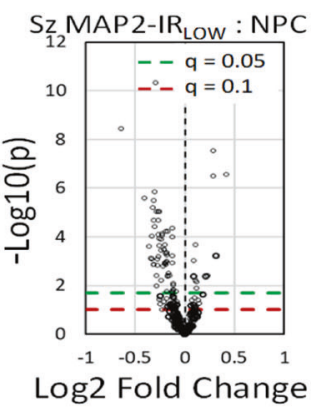

Fig. 5 co-IP of MAP2 from mouse brain and functional effects of S1782E on protein synthesis. a Using conservative cutoff criteria of $q<0.05,6095$ peptides (red) from 590 proteins were identified as potential MAP2 interactors. b Puromycin incorporation was detected via western blotting following a $1 \mathrm{~h}$ treatment of transiently transfected HEK293 cells expressing MAP2c-WT or MAP2c-S426E in comparison to cells transfected with eGFP control for $48 \mathrm{~h}$. Densitometric quantification of relative puromycin incorporation normalized to MAP2 expression levels. $N=4$, data shown are average across

subjects, dividing them into those in whom MAP2-IR was reduced (MAP2-IR $\mathrm{LOW}_{\text {) }}$ ) or intact $\left(\mathrm{MAP} 2-\mathrm{IR}_{\mathrm{NL}}\right)$. Reduced synaptosome protein levels were restricted to the MAP2$\mathrm{IR}_{\mathrm{LOW}} \mathrm{Sz}$ group (Fig. 5c), similar to that seen in S1782E mice, although with only $N=4$ mice/genotype the $p$ values are higher in the mice than in the postmortem study.
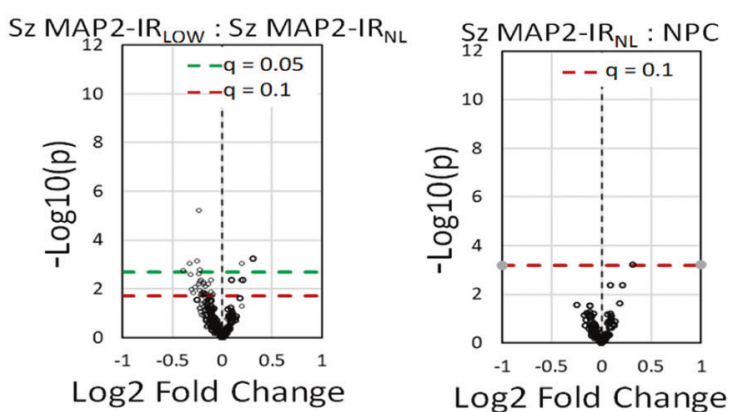

experiments \pm SEM. $* p<0.1, * * p<0.05$. c Reductions in the synaptic

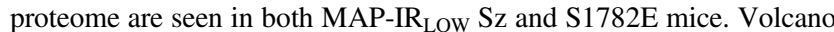
plots showing distribution of 159 synaptically enriched proteins in NPC, MAP2-IR LOW $_{1}$ and MAP2-IR $\mathrm{NL} \mathrm{Sz}(N=45$ pairs; $N=19$ MAP2-IR ${ }_{\mathrm{NL}}, N=26$ MAP2-IR $\left.{ }_{\mathrm{LOW}}\right)$. Mice with phosphomimetic mutation S1782E have synaptic proteome alterations similar to those seen in MAP2-IR LOW $_{\text {Sz }}(N=4$ mice/genotype). Green dashed line indicates $q$-value of 0.05 , red dashed line indicates $q$-value of 0.1 .

\section{Discussion}

MAP2 is the predominant dendritic MAP in the brain, where its modification by phosphorylation downstream of glutamate signaling [16] has been postulated to be a requisite step linking experience to structural plasticity of 
dendrites [61]. We implemented a phosphoproteomics approach to evaluate this posttranslational modification of MAP2 in Sz subjects in comparison to NPC subjects. We identified multiple abnormally phosphorylated MAP2 peptides, located predominantly in the Proline Rich and Cterminal domains which flank the MTB domain and are present in all isoforms. The most altered site was pS1782, which was found to be increased nearly eightfold in $\mathrm{Sz}$ subjects compared to NPC subjects. We carefully considered potential confounds (e.g., PMI, pH, tissue storage time, age, race, sex, antipsychotic treatment, substance use, tobacco use) in our human subjects, none of which accounted for the elevation in phosphopeptides in Sz. Instead, a module of co-occurring phosphopeptides including pS1782, correlated with increasing severity of structural, proteomic, and functional measures in our subjects, suggesting the possibility that some or all of these cooccurring phosphorylations may causally contribute to the pathogenesis of Sz. To evaluate potential causality, we chose the most elevated phosphorylation, pS1782, as a candidate for further study.

Prior studies have shown that phosphorylation of MAP2 within its MTB domain and proline rich domains reduce MT binding by MAP2 [13], and thus alter their dynamics [62]. However, the effects of phosphorylation are anticipated to be site specific, and prior studies have not evaluated phosphorylation at S1782. Given the proximity of S1782 to the MTB domain of MAP2, we utilized computational modeling to predict the effects of this modification on structure. We now show that phosphorylation of S1782 in the C-terminal domain of MAP2 can act similarly to phosphorylation at the homologous S396 in tau, which (in combination with $\mathrm{pS} 404$ ) is primarily responsible for tau dissociating from MTs [63]. Subsequent in vitro studies confirmed this finding, demonstrating reduced MT binding in an S426E (MAP2c) phosphomimetic construct.

Dendritic length and branching determine a PCs receptive field [64, 65], help to segment computational compartments [66], and contribute substantially to how the received signals are integrated and transmitted to the cell body $[67,68]$. Similarly, dendritic spines serve to segregate synaptic afferents [69]. Reduced dendritic arborization and DSD have consistently been found in postmortem studies of $\mathrm{Sz}$ [2], and impaired frequency discrimination is a hallmark of the disease [70]. Since dendrites are a principal component of cortical gray matter, it is possible that their reduction in $\mathrm{Sz}$ is a contributing factor to the observed reductions in gray matter volumes in disease [71-76]. Our data suggest that pathologic hyperphosphorylation at S1782 in MAP2 leads to reductions in basilar dendritic length and complexity similar to those seen in Sz and likely directly contributes to disease pathology. Similarly, reduced DSD has more recently been shown to directly correlate with
MAP2-IR [32]. Our analysis of S1782E mice demonstrates similar reductions in DSD to those described in Sz, suggesting that hyperphosphorylation at this site directly contributes to impairments in DSD.

While our current findings demonstrate the functional consequences of S1782E specifically, they should not be interpreted as a model of Sz per se, in which other MAP2 phosphorylations are also present. For example, we did not replicate in S1782E mice the loss of MAP2-IR present in SZ, suggesting that other phosphorylation events on MAP2, either in isolation or in combination with S1782, are likely responsible for the loss of MAP2-IR in SZ. In keeping with this observation, we found that MAP2-IR in human brain was most highly correlated with levels of a different phosphopeptide RLS[+80]NVSS[+80]SGS[+80]INLLESPQL ATLAEDVTAALAK $(r=0.62 ; p<001)$. Thus, each pathologically altered MAP2 phosphorylation event may affect MAP2 structure and/or function differently, ultimately converging onto a commonality of disruption of normal MAP2 function and subsequent disease pathology. Moreover, at least one prior study has reported changes in IR of an alternate MAP, MAP1B, in Sz [5]. MAP1B can partially compensate for loss of MAP2, and correspondingly, concurrent knockdown of both generates a more severe impairment in neuron structure [77].

Our computational models similarly identified a set of $\beta$ strands induced by $\mathrm{S} 1782$ phosphorylation between K368V372 and A420-Q425 (K1724-V1728 and A1776-Q1781 in canonical MAP2b numbering), a more open configuration that provides additional conformational combinations required for protein-protein interaction and thus the potential for an additional gain of pathologic functions. Specifically, we hypothesized that the reduced MTB affinity caused by (pseudo)phosphorylation of S1782 would lead to increased MT-unbound MAP2 levels. Previous work has shown binding by some proteins to only MT-unbound MAP2 [78], suggesting that a careful balance between MTbound and MT-unbound MAP2 may be necessary for proper cellular functioning. Hence, this increase, in combination with new protein interactions enabled by the conformational changes, provides a means by which phosphorylation of MAP2 may yield additional pathological gains of function in Sz. To determine the nature of these additional functions, we combined immunoenrichment with LC-MS/MS to characterize the MAP2 interactome. These studies revealed that the MAP2 interactome was enriched for interactions with ribosome and RNA-binding proteins forming the translational machinery (Tables S3 and S4). This finding is unlikely to be artifactual, as we eliminated the possibility of residual RNA binding through RNAse treatment prior to the co-IP. This finding suggests a novel role for MAP2 in regulation of protein translation. To determine the nature of this alternative function of MAP2, 
we used puromycin incorporation to measure protein synthesis. We found that overexpression of MAP2c suppresses protein translation in vitro, an effect which is slightly, though nonsignificantly, enhanced by pseudophosphorylation at S426 MAP2c (S1782 in MA2P2b). However, because this observation was obtained in HEK293 cells, which are not a neuronal cell line, we looked for convergent evidence of this effect in neurons, without the potential bias of overexpression of WT and phosphomimetic MAP2. We therefore evaluated a complementary measure, synaptic protein levels (rather than measuring protein synthesis per se), in mouse brain tissue. We found reduced levels of multiple synaptic proteins in synaptosomes of S1782E in comparison to WT mice. The possibility that repression of synaptic protein synthesis by pMAP2 has a role in the pathogenesis of $\mathrm{Sz}$ is further supported by our findings of reduced levels of multiple synaptic proteins in synaptosomes of MAP2-IR $\mathrm{L}_{\mathrm{Low}}$, but not MAP2-IR $\mathrm{NL}_{\mathrm{NL}}$, subjects with Sz. Taken together, these findings are the first to suggest that MAP2 may have an additional function in regulating protein translation and that phosphorylation at this site, alone or in combination with other phosphorylation sites, may alter this novel function of MAP2.

Long-standing findings have established that MAP2 is phosphorylated in response to synaptic activity that induces plasticity $[79,80]$. Recent studies have illuminated these prior observations, including direct demonstration that MAP2 is required for long-term potentiation (LTP) [81], a process dependent on new protein synthesis. Our replication of findings of an association of MAP2 with the protein translation machinery [57, 82, 83], and more importantly our novel demonstration that overexpression of WT or S426E MAP2 inhibits protein synthesis, provide a potential mechanism by which phosphorylation of MAP2 may impact LTP. A number of mRNAs are translated explicitly in dendrites after synaptic stimulation to provide rapid regulation of local protein levels in support of structural and functional plasticity [84]. Our findings that WT MAP2 and S426E/S1782E MAP2 inhibit protein synthesis and reduce synaptic protein levels suggest MAP2 may impact this process. However, the presence of multiple ribosomal proteins in our co-IP of MAP2 likely reflects many indirect interactions of proteins within the ribosomal complexes. MAP2 has been previously shown to interact directly with $\mathrm{KH}$ domains that are present in some RNA-binding proteins [83]. Our MAP2 co-IP from mouse brain included multiple such $\mathrm{KH}$ domain containing proteins (HNRNPK_Mouse, FMR1_Mouse, PCBP1_Mouse, PCBP2_Mouse, PCBP3_Mouse), identifying them as candidates for mediating the interaction of MAP2 with ribosomal complexes and the inhibition of protein translation.

In summary, we identified a novel pathology of Sz, differential phosphorylation of multiple peptides within
MAP2. We further demonstrated that at least one of these phosphorylations, pS1782, impairs MAP2 MT binding, reduces dendritic length, complexity, and DSD, and inhibits new protein synthesis-a function critical for dendritic spine plasticity. MAP2-IR has been shown to be reduced in multiple different regions of the cerebral cortex in $\mathrm{Sz}$ $[2,33]$, and we recently showed that the magnitude of this reduction is conserved across multiple cortical regions within individuals with $\mathrm{Sz}$ [85]. Similarly, reduced dendritic length, complexity, and DSD have been described across regions of the cerebral cortex in $\mathrm{Sz}$ [2]. Thus, although the current study findings were obtained in auditory cortex, they are likely to generalize across the cerebral cortex and provide a new conceptual framework for $\mathrm{Sz}$ as a "MAP2opathy." That is, differential phosphorylation of MAP2, like its homolog tau in dementia pathogenesis, may mediate impairments of neuronal structure and function downstream of many different genetic (and possibly environmental) risk factors. The potential impact of this conceptualization is that it identifies a bottleneck of molecular pathology providing a narrow set of targets for prevention and treatment for a large proportion of individuals with $\mathrm{Sz}$, regardless of the polygenic origins of their illness. Identification of the specific binding partner(s) of MAP2 within the protein translational machinery may provide leads to small molecules or peptides that disrupt this interaction and could then be tested as novel therapies for these individuals.

\section{Methods}

\section{Human subjects and animals}

Tissue was obtained from postmortem brains recovered during autopsies conducted at the Allegheny County Medical Examiner's Office, Pittsburgh, PA, following informed consent from the next of kin. All procedures were approved by the University of Pittsburgh Committee for the Oversight of Research and Clinical Trials Involving the Dead and the Institutional Review Board for Biomedical Research as previously described [26, 31]. An independent committee of experienced clinicians made consensus diagnoses, or absence thereof, according to the Diagnostic and Statistical Manual of Mental Disorders, Fourth Edition, for each subject using medical records, structured interviews with surviving relatives, and, when available, toxicology reports. For the phosphoproteomics, 16 individuals with a consensus diagnosis of $\mathrm{Sz}$ and 16 matched NPC subjects, all of whom had been previously characterized for MAP2-IR and DSD [32], and had available protein extracted from auditory cortex gray matter were studied (Table S1). The Sz subjects in this cohort were further divided by MAP2-IR as either

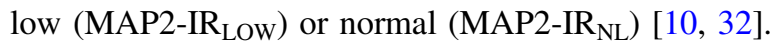


In order to account for the effects of chronic antipsychotic drug administration, a cohort of 18 male rhesus monkeys, $N=6$ per group, were administered therapeutically relevant doses of haloperidol, olanzapine, or vehicle, and monkeys were sacrificed in matched triads and tissue was immediately harvested and processed [33]. The tissue utilized here has been extensively described elsewhere $[86,87]$. Briefly, tissue slabs containing the superior temporal gyrus were removed in a single block and $20 \mathrm{mg}$ of gray matter was harvested as described above. A mouse model of PMI was generated using WT C57/B16J mice purchased from Jackson Laboratories (Bar Harbor, ME, USA). Adult mice, $N=2$ per timepoint (0, 6, 12, 18, $24 \mathrm{~h})$, were sacrificed by $\mathrm{CO}_{2}$ asphyxiation followed by cervical dislocation. The carcasses were incubated at room temperature for $2 / 3$ the PMI duration and then placed at $4{ }^{\circ} \mathrm{C}$ for the final $1 / 3$. The brain was then removed from the skull, the cerebellum discarded, and the hemispheres separated (giving $N=4$ hemispheres/timepoint), flash frozen in isopentane on dry ice, and stored at $-80{ }^{\circ} \mathrm{C}$ until use.

\section{Phosphoproteomics}

\section{Sample preparation-phosphopeptide enrichment}

Gray matter from frozen right hemisphere tissue blocks containing Heschl's gyrus was harvested as previously described [88]. Protein quantification was determined by using a micro bicinchoninic acid assay. The samples were processed across multiple runs, using a balanced block design to evenly distribute $\mathrm{Sz}$ and control subjects. Each run was processed identically. To account for biological and experimental variation, pooled controls were included in the designed and interspersed throughout. Five hundred micrograms of protein from each gray matter homogenate sample were in-solution digested overnight at $37^{\circ} \mathrm{C}$ with trypsin at a ratio of 1:50 ( $\mu \mathrm{g}$ trypsin: $\mu \mathrm{g}$ total protein). Samples were then desalted using Oasis cartridges. Phosphorylated peptides were enriched using titanium dioxide phosphoenrichment. To perform the titanium dioxide phosphoenrichment, TopTips $\mathrm{TiO}_{2}+\mathrm{ZrO}_{2}$ (Glygen Corporation, Columbia, MD, USA)) were washed three times with loading buffer (19\% lactic acid, $80 \%$ acetonitrile $(\mathrm{ACN}), 1 \%$ formic acid) and centrifuged $30 \mathrm{~s} \times 0.5 \mathrm{~g}$. Beads were suspended to $50 \%$ slurry with the loading buffer and $20 \mu \mathrm{L}$ of bead slurry was added to each sample. The sample + bead mixtures were rotated for $1 \mathrm{~h}$. Samples were spun $30 \mathrm{~s} \times 0.5 \mathrm{~g}$ and supernatant was removed. One milliliter of the loading buffer was added to each sample, and rotated for 5 min. Samples were centrifuged and supernatant removed. Sample was suspended in $200 \mu \mathrm{L}$ washing buffer $(80 \%$ ACN, 5\% TFA) and centrifuged through a C18 Stage tip. C18 stage tip was subsequently washed $\times 4$ with washing buffer. Phosphopeptides were eluted with $50 \mu \mathrm{L}$ elution buffer $(450 \mu \mathrm{L}$ ammonium hydroxide $(28 \%)$ in $4.5 \mathrm{~mL}$ DI $\mathrm{H}_{2} \mathrm{O}$, pH 11) two times. Elution buffer was evaporated and samples resuspended in $20 \mu \mathrm{L} 98 \%$ buffer A $(0.1 \%$ formic acid/DI $\left.\mathrm{H}_{2} \mathrm{O}\right) 2 \%$ buffer B (0.1\% formic acid/ACN). Samples were then analyzed by LC-MS/MS.

\section{Liquid chromatography-tandem mass spectrometry: phosphopeptides}

Phosphopeptide enrichments were analyzed by reversedphase nanoflow liquid chromatography-tandem mass spectrometry (nLC-MS/MS) using a nanoACQUITY (Waters Corporation, Milford, MA, USA) coupled to an Orbitrap XL hybrid ion trap mass spectrometer (Thermo Fisher Scientific, Waltham, MA, USA). Approximately one microgram of phosphopeptides was eluted over a 60-min gradient from $95 \%$ buffer A ( $2 \% \mathrm{ACN}, 0.1 \%$ formic acid) to $35 \%$ buffer B (ACN, $0.1 \%$ formic acid) on a $3 \mu \mathrm{m} 120 \mathrm{~A}$, 205 mm REPROSIL-Pur C18 PicoChip (New Objective). Sample eluate was electrosprayed $(2000 \mathrm{~V})$ into a Thermo Scientific Orbitrap XL mass spectrometer for analysis. The instrument was operated in MS2, top 4. MS1 spectra were acquired at a resolving power of 60,000. MS2 spectra acquired in the ion trap with CID normalized collision energy $=35$. Dynamic exclusion was enabled to minimize the redundant selection of peptides previously selected for MS/MS. Ion chromatograms of ten selected peptides were extracted using Skyline software (version 3.5) [89] and used to monitor during the instrumental analysis to ensure robust instrument performance.

\section{MS/MS data processing}

MS/MS spectra from the phosphopeptide experiment were searched using MASCOT search engine (Version 2.4.0, Matrix Science Ltd, Boston, MA, USA) against the UniProt human proteome database. The following modifications were used: static modification of cysteine (carboxyamidomethylation, $+57.05 \mathrm{Da}$ ), variable modification of methionine (oxidation, +15.99 Da), and variable modification of serine, threonine, and tyrosine (phosphorylation, +79.67 Da). The mass tolerance was set at $20 \mathrm{ppm}$ for the precursor ions and $0.8 \mathrm{Da}$ for the fragment ions. Peptide identifications were filtered using PeptideProphet ${ }^{\mathrm{TM}}$ and ProteinProphet ${ }^{\oplus}$ algorithms with a protein threshold cutoff of $99 \%$ and peptide threshold cutoff of $90 \%$ implemented in Scaffold $^{\mathrm{TM}}$ (v4.7.5; Proteome Software, Portland, Oregon, USA). Skyline MS1 filtering [90] was used for batched integration of ion chromatograms of all identified peptides. MS2 spectra for MAP2 were manually sequenced to confirm the phosphopeptide-spectra match and confidence of phospho-site assignment. 


\section{Preparation of expression constructs}

IRES-MAP2c-EGFP plasmids containing cDNAs encoding human MAP2c (NM_031845) were purchased from GeneCopoeia $^{\text {TM }}$ (Cat\#: CS-E2438-M61-01). Although MAP2c is a shorter isoform, we use the amino acid numbering designated by full-length MAP2 throughout unless specifically referring to an experiment using the MAP2c plasmid (i.e., S426 in MAP2c corresponds to S1782 using numbering based on the canonical MAP2b isoform). MAP2c phosphomimetic mutant S426E was generated using the QuikChange Lightning Site-directed Mutagenesis Kit (Agilent Technologies) and mutagenized primers (Table S5). Plasmids were purified using the EndoFree Plasmid Maxi Kit (Qiagen). Presence of the mutation at the desired site without additional off-target effects was evaluated by Sanger sequencing (Table S5). Transfection with the IRESEGFP plasmid (eGFP) lacking the MAP2c construct was used as a control.

\section{Cell culture and transfection}

HEK293 cells were purchased from ATCC and grown in RPMI-1640 containing 5\% fetal bovine serum (Cellgro, Manassas, VA) without antibiotics. They were grown in a humidified chamber at $37^{\circ} \mathrm{C}$ with $5 \% \mathrm{CO}_{2}$. They were passaged appropriately during linear growth phase to maintain subconfluent culture. For transfections they were seeded at $1.5 \times 10^{5}$ cells/well into 12 -well culture-treated plates. They were serum starved for $16 \mathrm{~h}$ overnight, then replenished with complete media at the time of transfection the following morning.

\section{Transfection}

All transfections were performed using Lipofectamine LTX with Plus Reagent (Thermo Fisher Scientific, Grand Island, $\mathrm{NY}$ ) in the absence of antibiotics. Media was changed $16 \mathrm{~h}$ after transfection.

\section{Western blotting}

Cell-free protein lysates were obtained from cells using radioimmune precipitation assay buffer $(10 \mathrm{mM}$ Tris- $\mathrm{HCl}$, pH 8.0, $1 \mathrm{mM}$ EDTA, pH 8.0, 0.5 mM EGTA, $140 \mathrm{mM}$ $\mathrm{NaCl}, 1 \%$ Triton $\mathrm{X}-100,0.1 \%$ sodium deoxycholate, $0.1 \%$ SDS), and total protein levels were quantified using the Lowry protein assay (Bio-Rad). Fifteen micrograms of total protein was loaded per well. Samples were electrophoresed on a NuPage Bis-Tris 4-12\% gradient polyacrylamide gel (Thermo Fisher Scientific) and transferred to a PVDF membrane (Millipore, Danvers, MA) at $100 \mathrm{~V}$ for $1 \mathrm{~h}$. Membranes were blocked in Licor Blocking Buffer
(Odyssey, Lincoln, NE) for $1 \mathrm{~h}$ at room temperature and primary antibody was added and incubated overnight at $4^{\circ}$ C. The following primary antibodies were used in this study: mouse anti-MAP2 (HM-2, Abcam, 1:1000), rabbit anti- $\beta$ tubulin (Abcam, 1:10,000), and mouse antipuromycin (12D10, Millipore Sigma, 1:25,000). Membranes were washed $5 \times 5 \mathrm{~min}$ in TBS containing $0.1 \%$ Tween and incubated with fluorescent-conjugated secondary antibodies $(1: 10,000)$ for $1 \mathrm{~h}$ at room temperature. Five more washes were performed and membranes were imaged using the Odyssey Licor System. Densitometric analyses were performed using MCID Core Analysis software (UK).

\section{CRISPR/Cas9 mouse generation}

\section{Reagent production}

An sgRNA targeting MAP2 was selected using CRISPOR [91]. An sgRNA specific forward primer and a common overlapping reverse PCR primer (see Table S6) were used to generate a $\mathrm{T} 7$ promoter containing sgRNA template as described [92]. This DNA template was transcribed in vitro using a MEGAshortscript Kit (Ambion). The Cas9 coding sequence was amplified from pX330 [93] using a T7 promoter containing forward primer and reverse primer (see Table S6) and subcloned into pCR2.1-TOPO. This plasmid was digested with EcoRI and the $\sim 4.3 \mathrm{~kb}$ fragment was in vitro transcribed and polyA tailed using the mMessage mMachine T7 Ultra Kit (Ambion). Following synthesis, the sgRNAs and Cas9 mRNA were purified using the MEGAclear Kit (Ambion), ethanol precipitated, and resuspended in DEPC treated water. A single stranded 130 nucleotide DNA repair template (see Table S6) harboring the knock-in sequences (TCC changed to GAG) and sequences homologous to MAP2 were purchased as Ultramer DNA (Integrated DNA Technologies, Coralville, IA). The oligo included three phosphorothioate linkages on each end [94], was asymmetrically oriented with respect to the PAM, and was complementary to the nontarget strand [95].

\section{Knock-in mouse production}

sgRNA (200 ng/ $\mu \mathrm{L})$, Cas 9 mRNA (200 ng/ $\mu \mathrm{L}, \quad$ NEB cat\#M0646), and the repair oligo $(200 \mathrm{ng} / \mu \mathrm{L})$ were mixed for electroporation using a Bio-Rad Gene Pulser XCell and custom electroporation chamber (Protech International Inc., cat\# LF501-P1X10). sgRNAs and protein were diluted with Opti-MEM (Thermo Fisher Scientific) prior to electroporation; OMEM constituted at least $50 \%$ of the electroporation solution. Electroporation conditions consisted of five repeats of $3 \mathrm{~ms}^{2}$ wave pulses of $25 \mathrm{~V}$ with $100 \mathrm{~ms}$ intervals. Following electroporation, embryos were washed in M2 and transferred to KSOM for culture prior to embryo 
transfer. Embryos were transferred as two cells to the oviducts of day 0.5 postcoitum pseudo pregnant CD-1 females.

\section{Mouse genotype analysis}

Mice were genotyped by PCR amplification (see Table S6 for primer sequences, MAP2 F1 and MAP2 R1) followed by restriction digestion with BspLI (FastDigest) to produce PCR amplicons that were either 487 bp (WT) or $337 \mathrm{bp}+$ 150 bp (knock-in). Undigested PCR amplicons of founder and all F1 offspring were also analyzed by Sanger sequencing.

\section{Off-target analysis}

The top ten predicted off-target sites (see Table S7) using CRISPOR software were analyzed by PCR amplification followed by Sanger sequencing.

\section{Mouse production}

A single male that was confirmed to be heterozygous for the mutation and free of off-target effects was chosen as the founder for line generation. He was mated with WT C57BL/6J females purchased from Jackson Laboratories (Bar Harbor, ME) and all F1 mice were genotyped by both PCR and restriction digest as well as confirmatory Sanger sequencing to establish the MAP2 S/E line. Heterozygotes were backcrossed into purchased WT C57BL/6J strain to produce animals for all experimental studies mitigating against genetic drift of the line. Throughout the text animals are referred to as S1782E mice.

Animals were identified with metal ear tags and tail snip DNA samples were obtained for genotyping by PCR prior to weaning at approximately postnatal day 21 . Genotypes of all mice included in studies were confirmed following sacrifice. Both male and female animals were included in all studies. Animals were under specific pathogen free conditions and housed in standard microisolator caging (Allentown Caging Equipment, Allentown, NJ, USA) in groups of up to four males or five females, maintained on a 12-h light/ dark cycle (lights on at 7 a.m.), and were provided with food and water ad libitum. All experimental procedures were approved by the Institutional Animal Care and Use Committee at the University of Pittsburgh.

\section{Golgi}

\section{Tissue generation}

Cohorts of mice were sacrificed at age 12 weeks \pm 3 days. Age-matched cohorts that included males and females of the

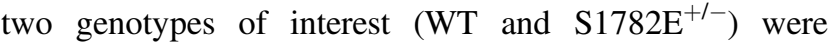

processed together throughout. Vaginal cytology was collected on all female mice at the time of sacrifice. Mice were sacrificed by lethal $\mathrm{CO}_{2}$ inhalation followed by decapitation and whole brain extraction. Golgi staining was performed using the FD Rapid GolgiStain Kit (FD Neurotechnologies, Inc) according to manufacturer's instructions. Brains were sectioned $(150 \mu \mathrm{m})$ on a cryostat. Tissue sections were placed onto gelatin-coated slides and allowed to dry overnight at room temperature. The following day, sections were then rehydrated with distilled and deionized water, reacted in a developing solution (FD Rapid GolgiStain Kit, FD Neurotechnologies), and dehydrated through graded ethanols. Finally, sections were cleared in xylene and coverslipped using Permount (Fisher Scientific). Auditory cortex was defined using gross anatomical landmarks and alignment with the corresponding Nissl plate containing A1 in the mouse brain atlas [96]. Within A1, deep layer 3 was defined as $30-50 \%$ of the distance between the pial surface and white matter border and sampling of pyramidal cells was performed as described below.

\section{Imaging}

For the analysis of dendritic structure in vivo, image acquisition was performed on a custom-built, wide-field epifluorescence Olympus IX73 microscope equipped with $\mathrm{XYZ}$-encoded prior stage, real-time autofocus, and a Hamamatsu ORCA-Flash4.0 sCMOS camera controlled with SlideBook 6.0 using an Olympus PlanAPOS 40× 0.90 NA air objective. Brightfield exposure time was optimized for each image. Image stacks, $1 \mu \mathrm{m}$ step size, through the entire tissue depth were captured of pyramidal shaped cells within the region of interest. Pyramidal cells were included if they did not have overlapping soma from neighboring cells and their soma was located roughly within $40-60 \%$ of the z-depth. Collected image planes were $2048 \times 2048$ pixels with a resolution of $0.161 \mu \mathrm{m} / \mathrm{pixel}$. A total of five neurons per animal distributed across two to three sections were collected from the right hemisphere. For dendritic reconstruction, image stacks were manually traced offline using Neurolucida software (Microbrightfield, Inc) and total dendritic content was analyzed via Sholl analysis using NeuroExplorer (Microbrightfield, Inc). Five animals per sex per genotype were included to allow for mixed effects modeling. Experimenter was blinded to the genotype throughout image acquisition and processing.

For the analysis of DSD, the same imaging system as described above was employed. PCs meeting the above criteria were identified at $\times 20$ magnification, and image stacks were subsequently collected using an Olympus PlanAPOS $60 \times 1.42 \mathrm{NA}$ oil objective at a step size of $0.7 \mu \mathrm{M}$. For spine counting, image stacks were manually evaluated offline using Stereo Investigator software (MBF Bioscience). For the 
analysis of spine density, we chose to focus on basilar dendrites. To be included in analysis a basilar dendrite was required to have $>75 \mu \mathrm{m}$ total length, branch at least once, and be free of overlapping dendrites that obscured accurate visualization. As DSD is not uniform across the entirety of the arbor [97], we ensured there was no difference across genotypes in average length (MAP2-WT $144.9 \pm 54.1 \mu \mathrm{m}$, MAP2 $\mathrm{S} / \mathrm{E} 145.8 \pm 72.2 \mu \mathrm{m}, p=0.95$ ) or number of branches (MAP2-WT 2.4 \pm 0.64 , MAP2 S/E $2.6 \pm 0.79, p=0.35$ ) of included dendrites. Three to five neurons per animal were included in the final analyses.

\section{MAP2 CO-IP}

\section{Tissue preparation and co-IP}

For co-IP from 4-week-old mouse brain tissue, mice were sacrificed by lethal $\mathrm{CO}_{2}$ followed by rapid decapitation. Whole mouse brains were then extracted, snap frozen, and stored at $-80{ }^{\circ} \mathrm{C}$ until use. Frozen brain tissue was manually homogenized in ice-cold 0.5\% NP-40 IP lysis buffer with RNAse ( $100 \mu \mathrm{L}$ per $1 \mathrm{~mL}$ of lysis buffer) by micropestle and passing through $23 \mathrm{G}$ needle multiple times. The lysate was then incubated on ice for $10 \mathrm{~min}$ followed by centrifugation at $14,000 \times g$ for $20 \mathrm{~min}$ at $4{ }^{\circ} \mathrm{C}$ to remove the insoluble fraction. The supernatant was centrifuged again at $12,000 \times g$ for $10 \mathrm{~min}$ at $4{ }^{\circ} \mathrm{C}$. The supernatant was transferred to a new tube, $50 \mu \mathrm{L}$ of which was saved as input, and the rest of the supernatant was precleared by incubation with $1 \mathrm{mg} 1 \mathrm{x}$ PBS prewashed Dynabeads (Thermo Fisher Scientific) on a rotator at $4{ }^{\circ} \mathrm{C}$ for $1 \mathrm{~h}$. To prepare the antibody-coupled beads, HM-2 antibody (Abcam, Cambridge, MA, USA) was incubated together with washed Dynabeads ( $8 \mu \mathrm{g}$ antibody per $\mathrm{mg}$ beads used) in 1x PBS buffer with $0.1 \mathrm{M}$ citrate $(\mathrm{pH} 3.1)$ on a rotator at $4{ }^{\circ} \mathrm{C}$ overnight. The precleared supernatant was incubated with antibody-coupled beads on a rotator at $4{ }^{\circ} \mathrm{C}$ overnight. Controls were generated using washed beads not coupled to antibody. Following overnight incubation, the supernatant was collected and saved in a new tube. The co-IP beads were washed three times in ice-cold 1x PBS buffer by gentle pipetting and directly boiled in $60 \mu \mathrm{L} 1 \mathrm{x}$ SDS sample buffer (30 mM Tris-HCl, pH 7.4, 1\% SDS, $12.5 \%$ glycerol, $2.5 \% \beta$-mercaptoethanol, $0.05 \%$ Orange $\mathrm{G}$ ) at $95^{\circ} \mathrm{C}$ for 10 min to elute protein complexes from the beads.

\section{In-gel trypsin digestion}

Immunoprecipitated samples were shortly separated $(1 \mathrm{~cm})$ by SDS-PAGE and stained with SimplyBlue ${ }^{\mathrm{TM}}$ SafeStain (Thermo Fisher Scientific). The stained gel regions were excised and in-gel trypsin digested as previously described [98]. In brief, the excised gel bands were washed with
HPLC water and destained with $50 \%$ ACN/25 mM ammonium bicarbonate until no visible staining. Gel pieces were dehydrated with $100 \%$ ACN, reduced with $10 \mathrm{mM}$ dithiothreitol (DTT) at $56^{\circ} \mathrm{C}$ for $1 \mathrm{~h}$, followed by alkylation with $55 \mathrm{mM}$ iodoacetamide (IAA) at room temperature for $45 \mathrm{~min}$ in the dark. Gel pieces were then again dehydrated with $100 \%$ ACN to remove excess DTT and IAA, and rehydrated with $20 \mathrm{ng} / \mu \mathrm{L}$ trypsin $/ 25 \mathrm{mM}$ ammonium bicarbonate and digested overnight at $37^{\circ} \mathrm{C}$. The resulting tryptic peptides were desalted with Pierce $\mathrm{C} 18$ Spin Columns, speed-vac dried, and resuspended in $18 \mu \mathrm{L} 0.1 \%$ formic acid. A pooled instrument control was made by taking $3 \mu \mathrm{L}$ from each of the samples.

\section{LC-MS/MS}

Extracted tryptic peptides were analyzed by nanoreversedphase liquid chromatography-tandem mass spectrometry (nLC-MS/MS) using a nanoACQUITY (Waters Corporation, Milford, MA, USA) online coupled with an Orbitrap Velos Pro hybrid ion trap mass spectrometer (Thermo Fisher Scientific). For each LC-MS/MS analysis, $1 \mu \mathrm{L}$ of peptides was injected onto a C18 column (PicoChip ${ }^{\mathrm{TM}} 25 \mathrm{~cm}$ column packed with Reprosil C18 $3 \mu \mathrm{m} 120 \AA$ A chromatography media with a $75 \mu \mathrm{m}$ ID column and $15 \mu \mathrm{m}$ tip; New Objective, Inc., Woburn, MA, USA) and then eluted off into the mass spectrometer with a 66 min linear gradient of $2-35 \%$ ACN/0.1\% $\mathrm{FA}$ at a $300 \mathrm{~nL} / \mathrm{min}$. A data-dependent top 13 method was used with full scan resolution set at 60,000. Ions were isolated for MS/MS analysis with a $2.0 \mathrm{Da}$ window. Dynamic exclusion and chromatograms from 20 selected peptides were utilized as described above.

\section{MS/MS data processing}

MS/MS spectra from the MAP2 co-IP experiment were searched and processed as described above for phosphoproteomic study using the mouse proteome database.

\section{Functional annotation analysis}

Peptides positively identified as potential MAP2 interactors (Table S4) were imported into DAVID (https://david. ncifcrf.gov/) and the conversion tool was used to identify 567 unique DAVID protein IDs within species Mus musculus. Mus musculus was selected as the background and functional annotation analysis was performed using the default settings (Table S5) [58].

\section{MTB assay}

Transfected HEK293 cells were harvested $48 \mathrm{~h}$ post transfection with ice-cold MTB buffer $(80 \mathrm{mM}$ Pipes, $5 \mathrm{mM}$ 
$\mathrm{MgCl} 2,0.5 \mathrm{mM}$ EGTA) supplemented with $1 \%$ Triton $\mathrm{X}-100$ and protease/phosphatase inhibitors (Millipore, Burlington, MA, USA, and Sigma, St. Louis, MO, USA, respectively) and lysed by vortex and passing through a $26 \mathrm{G}$ needle multiple times. Protein lysates were first centrifuged at $17,000 \times g$ for $10 \mathrm{~min}$ at $4{ }^{\circ} \mathrm{C}$ to remove insoluble cell debris, after which the supernatant was collected and further precleared by ultracentrifugation at $100,000 \times g$ for $40 \mathrm{~min}$ at $4{ }^{\circ} \mathrm{C}$. In vitro MTB assay was performed using the MTB protein spin down assay kit (Cytoskeleton, Denver, CO, USA) according to the manufacturer's instructions. Briefly, MTs were freshly polymerized and kept at room temperature prior to use. For each MTB reaction, $20 \mu \mathrm{L}$ freshly prepared MTs were incubated with a series of volumes $(10 \mu \mathrm{L} / 20 \mu \mathrm{L} / 30 \mu \mathrm{L})$ of precleared cell lysate for $30 \mathrm{~min}$ at room temperature. Precleared cell lysate alone in incubation reaction was included as negative control. Moreover, MAP fraction (contains $60 \%$ MAP2 at $280 \mathrm{kDa}$ and $40 \%$ tau proteins at $40-70 \mathrm{kDa}$ ) and BSA, each incubated with the polymerized MTs, served as a technical positive and negative control, respectively. Reaction solution was then placed on top of $100 \mu \mathrm{L}$ taxol supplemented cushion buffer ( $80 \mathrm{mM}$ PIPES, $\mathrm{pH} 7.0,1 \mathrm{mM} \mathrm{MgCl}$, $1 \mathrm{mM}$ EGTA, $60 \%$ glycerol) and centrifuged at $100,000 \times g$ for $40 \mathrm{~min}$ at room temperature. The pellets containing MTs and their binding proteins were resuspended in 1x SDS sample buffer as described above. Supernatant and pellet samples were analyzed by SDS-PAGE and Western blot.

\section{MD simulation}

The MD systems were built using cubic TIP3P water box with $12 \AA$ buffer around the solute following the general procedure of protein system building in CHARMM-GUI [99]. $\mathrm{Cl}-$ and $\mathrm{Na}+$ ions were added to the solvent to neutralize the charge of the systems. All MD simulations were performed using NAMD [100] and CHARMM C36m FF (optimized for disordered proteins) [101]. Secondary structure analysis of MD simulation trajectories were carried out using Timeline Plugin available within VMDv1.9.2 that utilizes STRIDE [102] for secondary structure analysis and an in-house script for identifying extended $\beta$ conformations that are not included as part of a $\beta$ sheet or hairpin using serial successive phi/psi angles. Initially all systems were minimized twice and then equilibrated them before beginning production runs. In the first minimization solute, atoms were held fixed through 500 steps of steepest descent and 500 steps of conjugate gradient minimization. In the second minimization, only the solute backbone atoms were restrained through 2000 steps of steepest descent and 3000 steps of conjugate gradient. After minimization, the system temperature was raised to $300 \mathrm{~K}$ over the course of a 100 ps constant volume simulation during which the solute is fixed with weak $(10.0 \mathrm{kcal} / \mathrm{mol})$ restraints. For the production run, the $500 \mathrm{~ns}$ simulations was held at constant temperature $300 \mathrm{~K}$ and under constant pressure of 1 bar without any restraints used during equilibration step. For this, Langevin dynamics was used to maintain constant temperature with a Langevin coupling coefficient of $1 / \mathrm{ps}$, and a Nosé-Hoover-Langevin piston was used to maintain constant pressure with a piston period of $50 \mathrm{fs}$ and a piston decay time of $25 \mathrm{fs}$ while keeping barostating isotropic. A 2 -fs timestep was used for integration together with the SHAKE algorithm where all covalent bonds between hydrogen and the heavy atom are constrained. The van der Waals interactions were smoothly switched off at 10-12 by a force-switching function while the long-range electrostatic interactions were calculated using the particle-mesh Ewald method.

\section{Surface sensing of translation (SUnSET) Assay}

SUnSET assay was performed as previously described [59] with minor modifications: HEK293 cells were incubated with $10 \mu \mathrm{g} / \mathrm{mL}$ of puromycin in cell culture media for $1 \mathrm{~h}$ before harvest. As a negative control, cells were pretreated with $10 \mu \mathrm{L}$ of cycloheximide to inhibit protein synthesis for $1 \mathrm{~h}$ before puromycin treatment. No puromycin incorporation was detected under these conditions (data not shown). Levels of newly synthesized proteins incorporating puromycin were measured using western blots as described above.

\section{Synaptosome preparations}

Full methodological information for the generation of the synaptosome data on the human subject cohort has been previously published in [60]. To generate the synaptosome data from the $\mathrm{S} 1782 \mathrm{E}$ transgenic mouse line, gray matter from reproductively capable mice $(N=4$ WT, $7.5 \pm$ 0.6 weeks; $N=4$ S1782E $+/+, 8.3 \pm 3.3$ weeks) was homogenized and subjected to a sucrose density gradient centrifugation method [103]. Detailed methods for sample preparation, MS/MS, and data processing are fully described in [60].

\section{Statistical analysis}

ANCOVA was performed to detect the difference across $\mathrm{Sz}$ with MAP2-IR ${ }_{\mathrm{LOW}}, \mathrm{Sz}$ with MAP2-IR $\mathrm{NL}_{\mathrm{L}}$, and NPC samples in 18 MAP2 phosphopetides. PMI and assay run were adjusted as covariates. Fold changes, $p$ values, and $q$-values between each $\mathrm{Sz}$ group and control samples are presented (Fig. 2a).

We also analyzed the association between MAP2 phosphopetides and each demographical or clinical variable 
using a similar ANCOVA model to detect potential confounders, where diagnosis, PMI, and assay run were adjusted. $p$ values and $q$-values for each variable are presented (Table S3).

WGCNA [34] was used to investigate the pattern of coregulated phosphopeptide expression in all samples. Topological overlap matrix was used to identify modules with clustered phosphopetides. The three identified networks were visualized using Cytoscape. To quantitate the representation of expression levels in each module, we calculated the first principal component of modules given by WGCNA, referred to as the module-specific eigenpeptide. Linear regression models were fitted to model the correlation between each module-specific eigenpeptide and DSD, synaptic protein levels, and SES, with diagnosis ( $\mathrm{Sz}$ or control) adjusted.

For Sholl analyses, we averaged the neurons within each animal. Then, we plotted the average length or intersection count across all radii up to $140 \mu \mathrm{m}$, separated by genotype. We also plotted the trajectory of length or intersection count over radius for each genotype group. A linear-mixed effects model [104] was fitted for each length or intersection count, where radius (treated categorical), sex, genotype, and radius-by-genotype interaction were treated as the fixed effects, and mouse was treated as the random effect. To control for estrus phase, instead of the two-category sex, a four-category "sex" including male and three vaginal cytologies for the female cohort was included as a covariate in the final model. The analysis was performed with the PROC MIXED procedure in SAS 9.4. Spine density analysis was performed using a Student's $t$ test.

Statistical analyses for the MTB and puromycin incorporation assays were performed in SPSS software with oneway ANOVA and Bonferroni post hoc test to determine statistically significant differences for all the comparisons. All statistical tests were two-sided with $\alpha=0.05$. Data are displayed \pm standard error of mean (SEM).

Student's $t$ test on $\log 2$ transformed peptide peak area was used for the statistical inference to select Map2 interacting partners. A peptide was considered differentially ID'd if the $q$-value was $<0.1$ and a positive Map2 co-IP: control ratio value.

ANCOVA was performed to detect the difference in synaptosome proteins among three phenotype groups $(\mathrm{Sz}$ MAP2-IR low $_{1}, \mathrm{Sz}$ MAP2-IR $\mathrm{NL}$, NPC). PMI and assay run were adjusted as covariates. $p$ values and fold change values were generated and plotted for each group comparison.

Acknowledgements RAS was supported by Grant MH071533 and NARSAD Distinguished Investigator Grant from the Brain \& Behavior Research Foundation, and MJG was supported by Grant MH118513-01. The authors would like to thank Duncan R. Groebe, $\mathrm{PhD}, \mathrm{MBA}$, for assistance in the editing of this manuscript. The Tsinghua Educational Foundation North America and the University of Pittsburgh have an ongoing collaboration to allow visiting scholars from Tsinghua University to gain laboratory experience within a University of Pittsburgh affiliated laboratory.

Author contributions MJG performed co-IP experiments, Golgi reconstructions, data analysis and interpretation, and writing of the manuscript. XS performed MTB assay, puromycin incorporation, and contributed to the conceptualization of the project and first drafts of parts of the manuscript. MLM, MG, and NAY performed the phosphoproteomics and LC/MS-MS on co-IP samples. ZS and YD performed all advanced statistical and network analyses. RAD performed confirmatory experiments and contributed to the data interpretation and analysis. DAL contributed to data interpretation and analysis. GEH generated the transgenic mouse model and contributed to data interpretation and analysis. CC, KAP, and DSP performed computational modeling. RAS oversaw the project conceptualization, all data analysis and interpretation, and manuscript writing.

\section{Compliance with ethical standards}

Conflict of interest XS, a University of Pittsburgh affiliated visiting research scholar working in Dr. Sweet's lab from August 1, 2016 through July 31, 2018, received no financial support from Dr. Sweet and did not contribute to any NIH-funded aspects of this work. Other authors declare that they have no conflict of interest.

Publisher's note Springer Nature remains neutral with regard to jurisdictional claims in published maps and institutional affiliations.

Open Access This article is licensed under a Creative Commons Attribution 4.0 International License, which permits use, sharing, adaptation, distribution and reproduction in any medium or format, as long as you give appropriate credit to the original author(s) and the source, provide a link to the Creative Commons license, and indicate if changes were made. The images or other third party material in this article are included in the article's Creative Commons license, unless indicated otherwise in a credit line to the material. If material is not included in the article's Creative Commons license and your intended use is not permitted by statutory regulation or exceeds the permitted use, you will need to obtain permission directly from the copyright holder. To view a copy of this license, visit http://creativecommons. org/licenses/by/4.0/.

\section{References}

1. Kavanagh DH, Tansey KE, O’Donovan MC, Owen MJ. Schizophrenia genetics: emerging themes for a complex disorder. Mol Psychiatry. 2015;20:72-6.

2. Moyer CE, Shelton MA, Sweet RA. Dendritic spine alterations in schizophrenia. Neurosci Lett. 2015;601:46-53.

3. Lewis DA, Lieberman JA. Catching up on schizophrenia: natural history and neurobiology. Neuron. 2000;28:325-34.

4. Hegarty JD, Baldessarini RJ, Tohen M, Waternaux C, Oepen G. One hundred years of schizophrenia: a meta-analysis of the outcome literature. Am J Psychiatry. 1994;151:1409-16.

5. Arnold SE, Lee VM, Gur RE, Trojanowski JQ. Abnormal expression of two microtubule-associated proteins (MAP2 and MAP5) in specific subfields of the hippocampal formation in schizophrenia. Proc Natl Acad Sci USA. 1991;88:10850-4.

6. Jones LB, Johnson N, Byne W. Alterations in MAP2 immunocytochemistry in areas 9 and 32 of schizophrenic prefrontal cortex. Psychiatry Res. 2002;114:137-48. 
7. Rioux L, Ruscheinsky D, Arnold SE. Microtubule-associated protein MAP2 expression in olfactory bulb in schizophrenia. Psychiatry Res. 2004;128:1-7.

8. Rosoklija G, Keilp JG, Toomayan G, Mancevski B, Haroutunian $\mathrm{V}$, Liu D, et al. Altered subicular MAP2 immunoreactivity in schizophrenia. Prilozi. 2005;26:13-34.

9. Somenarain L, Jones LB. A comparative study of MAP2 immunostaining in areas 9 and 17 in schizophrenia and Huntington chorea. J Psychiatr Res. 2010;44:694-9.

10. Shelton MA, Newman JT, Gu H, Sampson AR, Fish KN, Macdonald ML, et al. Loss of microtubule-associated protein 2 immunoreactivity linked to dendritic spine loss in schizophrenia. Biol Psychiatry. 2015;78:374-85.

11. Marchisella F, Coffey ET, Hollos P. Microtubule and microtubule associated protein anomalies in psychiatric disease. Cytoskeleton. 2016;73:596-611.

12. McKinney BC, MacDonald ML, Newman JT, Shelton MA, DeGiosio RA, Kelly RM, et al. Density of small dendritic spines and microtubule-associated-protein-2 immunoreactivity in the primary auditory cortex of subjects with schizophrenia. Neuropsychopharmacology. 2019;44:1055-61.

13. Sanchez C, Diaz-Nido J, Avila J. Phosphorylation of microtubule-associated protein 2 (MAP2) and its relevance for the regulation of the neuronal cytoskeleton function. Prog Neurobiol. 2000;61:133-68.

14. Halpain S, Greengard P. Activation of NMDA receptors induces rapid dephosphorylation of the cytoskeletal protein MAP2. Neuron. 1990;5:237-46.

15. Quinlan EM, Halpain S. Postsynaptic mechanisms for bidirectional control of MAP2 phosphorylation by glutamate receptors. Neuron. 1996;16:357-68.

16. Quinlan EM, Halpain S. Emergence of activity-dependent, bidirectional control of microtubule-associated protein MAP2 phosphorylation during postnatal development. J Neurosci. 1996;16:7627-37.

17. Davare MA, Dong F, Rubin CS, Hell JW. The A-kinase anchor protein MAP2B and CAMP-dependent protein kinase are associated with class $\mathrm{C}$ L-type calcium channels in neurons. J Biol Chem. 1999;274:30280-7.

18. Hoshi M, Ohta K, Gotoh Y, Mori A, Murofushi H, Sakai H, et al. Mitogen-activated-protein-kinase-catalyzed phosphorylation of microtubule-associated proteins, microtubule-associated protein 2 and microtubule-associated protein 4 , induces an alteration in their function. Eur J Biochem. 1992;203:43-52.

19. Schizophrenia Working Group of the Psychiatric Genomics Consortium. Biological insights from 108 schizophrenia-associated genetic loci. Nature. 2014;511:421-7.

20. Purcell SM, Moran JL, Fromer M, Ruderfer D, Solovieff N, Roussos $\mathrm{P}$, et al. A polygenic burden of rare disruptive mutations in schizophrenia. Nature. 2014;506:185-90.

21. Salvoro C, Bortoluzzi S, Coppe A, Valle G, Feltrin E, Mostacciuolo $\mathrm{ML}$, et al. Rare risk variants identification by identity-by-descent mapping and whole-exome sequencing implicates neuronal development pathways in schizophrenia and bipolar disorder. Mol Neurobiol. 2018;55:7366-76.

22. Gusev A, Mancuso N, Won H, Kousi M, Finucane HK, Reshef $\mathrm{Y}$, et al. Transcriptome-wide association study of schizophrenia and chromatin activity yields mechanistic disease insights. Nat Genet. 2018;50:538-48.

23. Mohan R, John A. Microtubule-associated proteins as direct crosslinkers of actin filaments and microtubules. IUBMB Life. 2015;67:395-403.

24. Black JE, Kodish IM, Grossman AW, Klintsova AY, Orlovskaya $\mathrm{D}$, Vostrikov V, et al. Pathology of layer V pyramidal neurons in the prefrontal cortex of patients with schizophrenia. Am J Psychiatry. 2004;161:742-4.
25. Broadbelt K, Byne W, Jones LB. Evidence for a decrease in basilar dendrites of pyramidal cells in schizophrenic medial prefrontal cortex. Schizophr Res. 2002;58:75-81.

26. Glantz LA, Lewis DA. Decreased dendritic spine density on prefrontal cortical pyramidal neurons in schizophrenia. Arch Gen Psychiatry. 2000;57:65-73.

27. Konopaske GT, Lange N, Coyle JT, Benes FM. Prefrontal cortical dendritic spine pathology in schizophrenia and bipolar disorder. JAMA Psychiatry. 2014;71:1323-31.

28. Kalus P, Müller TJ, Zuschratter W, Senitz D. The dendritic architecture of prefrontal pyramidal neurons in schizophrenic patients. Neuroreport. 2000;11:3621-5.

29. Garey LJ, Ong WY, Patel TS, Kanani M, Davis A, Mortimer $\mathrm{AM}$, et al. Reduced dendritic spine density on cerebral cortical pyramidal neurons in schizophrenia. J Neurol, Neurosurg Psychiatry. 1998;65:446-53.

30. Rosoklija G, Toomayan G, Ellis SP, Keilp J, Mann JJ, Latov N, et al. Structural abnormalities of subicular dendrites in subjects with schizophrenia and mood disorders. Arch Gen Psychiatry. 2000;57:349-56.

31. Sweet RA, Henteleff RA, Zhang W, Sampson AR, Lewis DA. Reduced dendritic spine density in auditory cortex of subjects with schizophrenia. Neuropsychopharmacology. 2009;34: 374-89.

32. McKinney BC, MacDonald ML, Newman JT, Shelton MA, DeGiosio RA, Kelly RM, et al. Density of small dendritic spines and microtubuleassociated-protein-2 immunoreactivity in the primary auditory cortex of subjects with schizophrenia. Neuropsychopharmacology. 2019;44:1055-61.

33. Konopaske GT, Dorph-Petersen KA, Sweet RA, Pierri JN, Zhang W, Sampson AR, et al. Effect of chronic antipsychotic exposure on astrocyte and oligodendrocyte numbers in macaque monkeys. Biol Psychiatry. 2008;63:759-65.

34. Langfelder P, Horvath S. WGCNA: an R package for weighted correlation network analysis. BMC Bioinform. 2008;9:559.

35. MacDonald MGM, Newman J, Sun Z, Kannarkat J, Salisbury R, Glausier J, et al. Synaptic proteome alterations in the primary auditory cortex of schizophrenia. 2019. https://doi.org/10.1101/ 639914.

36. Glausier JR, Kelly MA, Salem S, Chen K, Lewis DA. Proxy measures of premortem cognitive aptitude in postmortem subjects with schizophrenia. Psychol Med. 2019:50:507-14.

37. Regan P, Piers T, Yi JH, Kim DH, Huh S, Park SJ, et al. Tau phosphorylation at serine 396 residue is required for hippocampal LTD. J Neurosci. 2015;35:4804-12.

38. Xia D, Li C, Gotz J. Pseudophosphorylation of tau at distinct epitopes or the presence of the P301L mutation targets the microtubule-associated protein tau to dendritic spines. Biochim Biophys Acta. 2015;1852:913-24.

39. Bramblett GT, Goedert M, Jakes R, Merrick SE, Trojanowski JQ, Lee VM. Abnormal tau phosphorylation at Ser396 in Alzheimer's disease recapitulates development and contributes to reduced microtubule binding. Neuron. 1993;10:1089-99.

40. Mondragon-Rodriguez S, Perry G, Luna-Munoz J, AcevedoAquino MC, Williams S. Phosphorylation of tau protein at sites Ser(396-404) is one of the earliest events in Alzheimer's disease and Down syndrome. Neuropathol Appl Neurobiol. 2014;40:121-35.

41. Jansen S, Melkova K, Trosanova Z, Hanakova K, Zachrdla M, Novacek J, et al. Quantitative mapping of microtubule-associated protein 2c (MAP2c) phosphorylation and regulatory protein 143-3zeta-binding sites reveals key differences between MAP2c and its homolog tau. J Biol Chem. 2017;292:6715-27.

42. Novacek J, Janda L, Dopitova R, Zidek L, Sklenar V. Efficient protocol for backbone and side-chain assignments of large, intrinsically disordered proteins: transient secondary structure 
analysis of $49.2 \mathrm{kDa}$ microtubule associated protein 2c. J Biomol NMR. 2013;56:291-301.

43. Lippens G, Landrieu I, Smet C, Huvent I, Gandhi NS, Gigant B, et al. NMR meets tau: insights into its function and pathology. Biomolecules. 2016;6:28.

44. Sillen A, Barbier P, Landrieu I, Lefebvre S, Wieruszeski JM, Leroy A, et al. NMR investigation of the interaction between the neuronal protein tau and the microtubules. Biochemistry. 2007;46:3055-64.

45. Schwalbe M, Kadavath H, Biernat J, Ozenne V, Blackledge M, Mandelkow E, et al. Structural impact of tau phosphorylation at threonine 231. Structure. 2015;23:1448-58.

46. Lyons AJ, Gandhi NS, Mancera RL. Molecular dynamics simulation of the phosphorylation-induced conformational changes of a tau peptide fragment. Proteins. 2014;82:1907-23.

47. Amniai L, Lippens G, Landrieu I. Characterization of the AT180 epitope of phosphorylated tau protein by a combined nuclear magnetic resonance and fluorescence spectroscopy approach. Biochem Biophys Res Commun. 2011;412:743-6.

48. Sibille N, Huvent I, Fauquant C, Verdegem D, Amniai L, Leroy A, et al. Structural characterization by nuclear magnetic resonance of the impact of phosphorylation in the proline-rich region of the disordered tau protein. Proteins. 2012;80:454-62.

49. Mukrasch MD, von Bergen M, Biernat J, Fischer D, Griesinger C, Mandelkow E, et al. The "jaws" of the tau-microtubule interaction. J Biol Chem. 2007;282:12230-9.

50. Gustke N, Trinczek B, Biernat J, Mandelkow EM, Mandelkow E. Domains of tau protein and interactions with microtubules. Biochemistry. 1994;33:9511-22.

51. Kadavath H, Jaremko M, Jaremko L, Biernat J, Mandelkow E, Zweckstetter M. Folding of the tau protein on microtubules. Angew Chem Int Ed. 2015;54:10347-51.

52. Harindranath K, Yunior CF, Mariusz J, Łukasz J, Kerstin O, Jacek B, et al. The binding mode of a tau peptide with tubulin. Angew Chem Int Ed. 2018;57:3246-50.

53. Jaworski J, Kapitein LC, Gouveia SM, Dortland BR, Wulf PS, Grigoriev I, et al. Dynamic microtubules regulate dendritic spine morphology and synaptic plasticity. Neuron. 2009;61:85-100.

54. Kapitein LC, Yau KW, Gouveia SM, van der Zwan WA, Wulf PS, Keijzer N, et al. NMDA receptor activation suppresses microtubule growth and spine entry. J Neurosci. 2011;31: 8194-209.

55. Xie C, Miyasaka T, Yoshimura S, Hatsuta H, Yoshina S, KageNakadai E, et al. The homologous carboxyl-terminal domains of microtubule-associated protein 2 and TAU induce neuronal dysfunction and have differential fates in the evolution of neurofibrillary tangles. PLoS ONE. 2014;9:e89796.

56. Gumy LF, Katrukha EA, Grigoriev I, Jaarsma D, Kapitein LC, Akhmanova A, et al. MAP2 defines a pre-axonal filtering zone to regulate KIF1- versus KIF5-dependent cargo transport in sensory neurons. Neuron. 2017;94:347-62.

57. Farah CA, Liazoghli D, Perreault S, Desjardins M, Guimont A, Anton A, et al. Interaction of microtubule-associated protein-2 and p63: a new link between microtubules and rough endoplasmic reticulum membranes in neurons. $J$ Biol Chem. 2005;280:9439-49.

58. Huang dW, Sherman BT, Lempicki RA. Systematic and integrative analysis of large gene lists using DAVID bioinformatics resources. Nat Protoc. 2009;4:44-57.

59. Schmidt EK, Clavarino G, Ceppi M, Pierre P. SUnSET, a nonradioactive method to monitor protein synthesis. Nat Methods. 2009;6:275-7.

60. MacDonald ML, Garver M, Newman J, Sun Z, Kannarkat J, Salisbury R, et al. Synaptic proteome alterations in the primary auditory cortex of individuals with schizophrenia. JAMA Psychiatry. 2020;77:86-95.
61. Johnson GV, Jope RS. The role of microtubule-associated protein 2 (MAP-2) in neuronal growth, plasticity, and degeneration. J Neurosci Res. 1992;33:505-12.

62. Itoh TJ, Hisanaga S, Hosoi T, Kishimoto T, Hotani H. Phosphorylation states of microtubule-associated protein 2 (MAP2) determine the regulatory role of MAP2 in microtubule dynamics. Biochemistry. 1997;36:12574-82.

63. Evans DB, Rank KB, Bhattacharya K, Thomsen DR, Gurney ME, Sharma SK. Tau phosphorylation at serine 396 and serine 404 by human recombinant tau protein kinase II inhibits tau's ability to promote microtubule assembly. J Biol Chem. 2000;275:24977-83.

64. Shepherd GM, Stepanyants A, Bureau I, Chklovskii D, Svoboda K. Geometric and functional organization of cortical circuits. Nat Neurosci. 2005;8:782-90.

65. Wen Q, Chklovskii DB. A cost-benefit analysis of neuronal morphology. J Neurophysiol. 2008;99:2320-8.

66. Cichon J, Gan WB. Branch-specific dendritic $\mathrm{Ca}(2+)$ spikes cause persistent synaptic plasticity. Nature. 2015;520:180-5.

67. Losonczy A, Makara JK, Magee JC. Compartmentalized dendritic plasticity and input feature storage in neurons. Nature. 2008;452:436-41.

68. Spruston N. Pyramidal neurons: dendritic structure and synaptic integration. Nat Rev Neurosci. 2008;9:206-21.

69. Chen X, Leischner U, Rochefort NL, Nelken I, Konnerth A. Functional mapping of single spines in cortical neurons in vivo. Nature. 2011;475:501-5.

70. Javitt DC, Sweet RA. Auditory dysfunction in schizophrenia: integrating clinical and basic features. Nat Rev Neurosci. 2015;16:535-50.

71. Hirayasu Y, McCarley RW, Salisbury DF, Tanaka S, Kwon JS, Frumin $\mathrm{M}$, et al. Planum temporale and Heschl gyrus volume reduction in schizophrenia: a magnetic resonance imaging study of first-episode patients. Arch Gen Psychiatry. 2000;57:692-9.

72. Hirayasu Y, Shenton ME, Salisbury DF, Dickey CC, Fischer IA, Mazzoni $\mathrm{P}$, et al. Lower left temporal lobe MRI volumes in patients with first-episode schizophrenia compared with psychotic patients with first-episode affective disorder and normal subjects. Am J Psychiatry. 1998;155:1384-91.

73. Honea R, Crow TJ, Passingham D, Mackay CE. Regional deficits in brain volume in schizophrenia: a meta-analysis of voxelbased morphometry studies. Am J Psychiatry. 2005;162: 2233-45.

74. Kasai K, Shenton ME, Salisbury DF, Hirayasu Y, Onitsuka T, Spencer MH, et al. Progressive decrease of left Heschl gyrus and planum temporale gray matter volume in first-episode schizophrenia: a longitudinal magnetic resonance imaging study. Arch Gen Psychiatry. 2003;60:766-75.

75. McCarley RW, Wible CG, Frumin M, Hirayasu Y, Levitt JJ, Fischer IA, et al. MRI anatomy of schizophrenia. Biol Psychiatry. 1999;45:1099-119.

76. Salisbury DF, Kuroki N, Kasai K, Shenton ME, McCarley RW. Progressive and interrelated functional and structural evidence of post-onset brain reduction in schizophrenia. Arch Gen Psychiatry. 2007;64:521-9.

77. Teng J, Takei Y, Harada A, Nakata T, Chen J, Hirokawa N. Synergistic effects of MAP2 and MAP1B knockout in neuronal migration, dendritic outgrowth, and microtubule organization. J Cell Biol. 2001;155:65-76.

78. Lim RW, Halpain S. Regulated association of microtubuleassociated protein 2 (MAP2) with Src and Grb2: evidence for MAP2 as a scaffolding protein. J Biol Chem. 2000;275: 20578-87.

79. Li J, Wilkinson B, Clementel VA, Hou J, O’Dell TJ, Coba MP. Long-term potentiation modulates synaptic phosphorylation 
networks and reshapes the structure of the postsynaptic interactome. Sci Signal. 2016;9:rs8.

80. Philpot BD, Lim JH, Halpain S, Brunjes PC. Experiencedependent modifications in MAP2 phosphorylation in rat olfactory bulb. J Neurosci. 1997;17:9596-604.

81. Kim Y, Jang YN, Kim JY, Kim N, Noh S, Kim H, et al. Microtubule-associated protein 2 mediates induction of longterm potentiation in hippocampal neurons. FASEB J. 2020;34: 6965-83.

82. Angenstein F, Evans AM, Ling SC, Settlage RE, Ficarro S, Carrero-Martinez FA, et al. Proteomic characterization of messenger ribonucleoprotein complexes bound to nontranslated or translated poly(A) mRNAs in the rat cerebral cortex. J Biol Chem. 2005;280:6496-503.

83. Nielsen FC, Nielsen J, Kristensen MA, Koch G, Christiansen J. Cytoplasmic trafficking of IGF-II mRNA-binding protein by conserved KH domains. J Cell Sci. 2002;115:2087-97.

84. Hanus C, Schuman EM. Proteostasis in complex dendrites. Nat Rev Neurosci. 2013;14:638.

85. DeGiosio R, Kelly RM, DeDionisio AM, Newman JT, Fish KN, Sampson AR, et al. MAP2 immunoreactivity deficit is conserved across the cerebral cortex within individuals with schizophrenia. NPJ Schizophr. 2019;5:13.

86. O'Connor JA, Hasenkamp W, Horman BM, Muly EC, Hemby SE. Region specific regulation of NR1 in rhesus monkeys following chronic antipsychotic drug administration. Biol Psychiatry. 2006;60:659-62.

87. O'Connor JA, Muly EC, Arnold SE, Hemby SE. AMPA receptor subunit and splice variant expression in the DLPFC of schizophrenic subjects and rhesus monkeys chronically administered antipsychotic drugs. Schizophr Res. 2007;90:28-40.

88. MacDonald ML, Ding Y, Newman J, Hemby S, Penzes P, Lewis DA, et al. Altered glutamate protein co-expression network topology linked to spine loss in the auditory cortex of schizophrenia. Biol Psychiatry. 2015;77:959-68.

89. MacLean B, Tomazela DM, Shulman N, Chambers M, Finney GL, Frewen B, et al. Skyline: an open source document editor for creating and analyzing targeted proteomics experiments. Bioinformatics. 2010;26:966-8.

90. Schilling B, Rardin MJ, MacLean BX, Zawadzka AM, Frewen BE, Cusack MP, et al. Platform-independent and label-free quantitation of proteomic data using MS1 extracted ion chromatograms in Skyline application to protein acetylation and phosphorylation. Mol Cell Proteom. 2012;11:202-14.

91. Haeussler M, Schonig K, Eckert H, Eschstruth A, Mianne J, Renaud JB, et al. Evaluation of off-target and on-target scoring algorithms and integration into the guide RNA selection tool CRISPOR. Genome Biol. 2016;17:148.

92. Bassett Andrew R, Tibbit C, Ponting Chris P, Liu J-L. Highly efficient targeted mutagenesis of Drosophila with the CRISPR/ Cas9 system. Cell Rep. 2013;4:220-8.

93. Cong L, Ran FA, Cox D, Lin S, Barretto R, Habib N, et al. Multiplex genome engineering using CRISPR/Cas systems. Science. 2013;339:819-23.

94. Renaud JB, Boix C, Charpentier M, De Cian A, Cochennec J, Duvernois-Berthet $\mathrm{E}$, et al. Improved genome editing efficiency and flexibility using modified oligonucleotides with TALEN and CRISPR-Cas9 nucleases. Cell Rep. 2016;2263-72.

95. Richardson CD, Ray GJ, DeWitt MA, Curie GL, Corn JE. Enhancing homology-directed genome editing by catalytically active and inactive CRISPR-Cas9 using asymmetric donor DNA. Nat Biotechnol. 2016;34:339-44.

96. Paxinos G, Franklin K. The mouse brain in stereotaxic coordinates. 3rd ed. San Diego: Academic Press; 2008.

97. Jacobs B, Schall M, Prather M, Kapler E, Driscoll L, Baca S, et al. Regional dendritic and spine variation in human cerebral cortex: a quantitative golgi study. Cereb Cortex. 2001;11: 558-71.

98. Braganza A, Li J, Zeng X, Yates NA, Dey NB, Andrews J, et al. UBE3B is a calmodulin-regulated, mitochondrion-associated E3 ubiquitin ligase. J Biol Chem. 2017;292:2470-84.

99. Jo S, Kim T, Iyer VG, Im W. CHARMM-GUI: a web-based graphical user interface for CHARMM. J Comput Chem. 2008;29:1859-65.

100. Phillips JC, Braun R, Wang W, Gumbart J, Tajkhorshid E, Villa E, et al. Scalable molecular dynamics with NAMD. J Comput Chem. 2005;26:1781-802.

101. Huang J, Rauscher S, Nawrocki G, Ran T, Feig M, de Groot BL, et al. CHARMM36m: an improved force field for folded and intrinsically disordered proteins. Nat Methods. 2017;14:71-3.

102. Andersen CA, Palmer AG, Brunak S, Rost B. Continuum secondary structure captures protein flexibility. Structure. 2002;10: $175-84$.

103. MacDonald ML, Ciccimaro E, Prakash A, Banerjee A, Seeholzer SH, Blair IA, et al. Biochemical fractionation and stable isotope dilution liquid chromatography-mass spectrometry for targeted and microdomain-specific protein quantification in human postmortem brain tissue. Mol Cell Proteom. 2012;11: 1670-81.

104. Wilson MD, Sethi S, Lein PJ, Keil KP. Valid statistical approaches for analyzing sholl data: mixed effects versus simple linear models. J Neurosci Methods. 2017;279:33-43. 